\title{
الحق بالتعلم بوصفه حقا جماعيا: جامعة عربية في إسرائيل! التحديات والعقبات والإحتمالات
}

\author{
د. نهاد علي \\ اكاديمية الجليل الغربي وجامعة حيفا- رئيس قسم المجتمع العربي بمؤسسة صاموئيل ننمان التخنيون \\ NohadAli@univ.haifa.ac.il
}

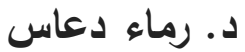

باحثه ومحاضرة في التربية- كلية القاسمي للتربية rimaajd@gmail.com

الملخص:

تحمل فكرة انشاء جامعة عربية في دولة إسرائيل الكثير من الخلافات في الرأي سواء داخل المجتمع العربي أو داخل المجتمع اليهودي بشكل أساسي والمؤسسة الإسرائيلية الحاكمة حيث تتال الفكرة معارضة كبيرة. وترى الغالبية العظمى من الجماهير العربية إن إنشاء جامعة عربية يمثل محاولة لخدمة المواطنين العرب في إسرائيل وتعزيز مكانتهم وحماية هويتهم وثقافتهر ووجودهم. وايضاً

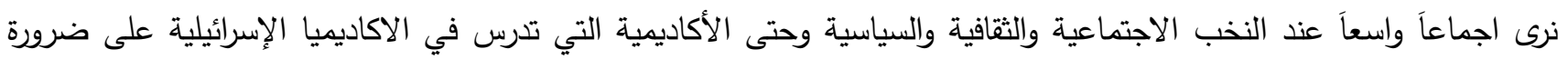

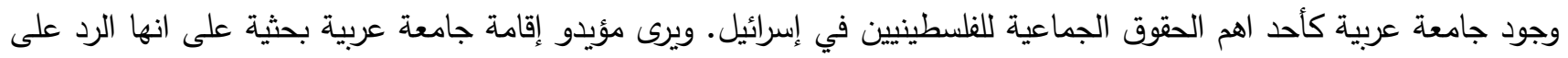

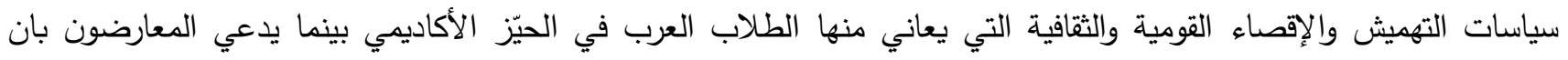

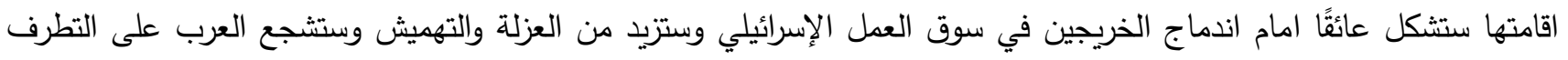
والعدائية للدولة الإسرائيلية.

تتاقش هذه المقالة البحثية رؤية إنشاء جامعة عربية: الحواجز والعقبات التي تواجهها، وعدم المساواة في الحقوق الأكاديمية، والطريقة التي يمكن بها تحقيق هذا الحلم. تتناول هذه المقالة أيضا ثلاثة ظواهر هي: ظاهرة "أردنة" التعليم العالي اي الدراسة العليا في الأردن، وظاهرة "فلسطنة" التعليم العالي اي الدراسة العليا في فلسطين وتدويل التعليم العالي اي الدراسة العليا في الدول الغربية وغيرها، وتستعرض الدراسة أحدث المعطيات عن التعليم العالي لدى العرب- الفلسطينيين في إسرائيل.

الكلمات الرئيسية: الجامعة العربية، بنية الثقافة العربية، الأقلية القومية العرقية، التمييز القومي، التهميش، البنية السياسية الإسرائيلية 


\section{المقدمة:}

يعتبر الحق في التعليم من الحقوق الأساسية التي كفلتها جميع المواثيق والمعاهدات الدولية والإقليمية، وقد وردت في ذلك عدة مواد في الإعلان العالمي لحقوق الإنسان، والعهد الدولي للحقوق الاقتصادية والاجتماعية والثقافية، واتفاقية حقوق الطفل،

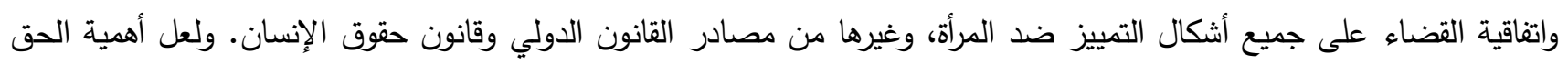

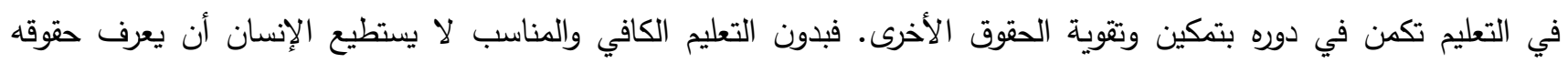
الأخرى ولا أن يميز حالات انتهاك حقوق الإنسان، ولا يمكنه أن يدافع عن تلك الحقوق. حيث أن أن خصوصية الحئ الحق في التعليم تتيح

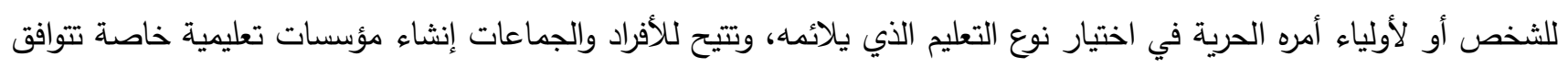

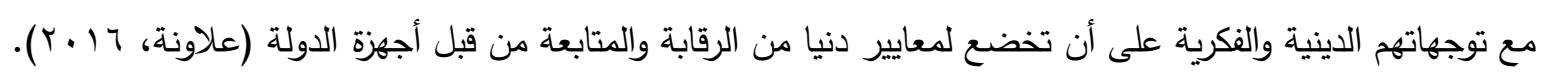

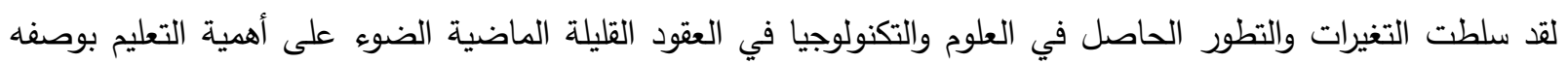

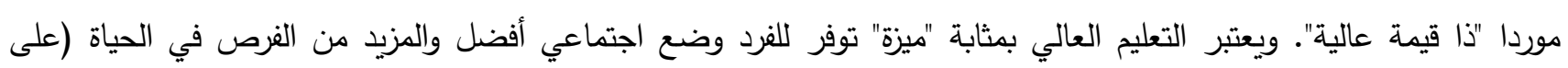

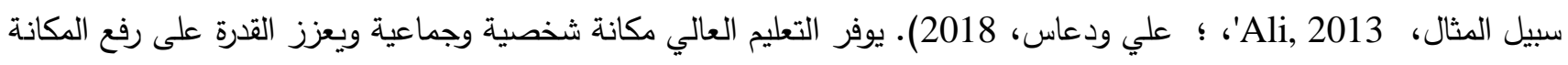

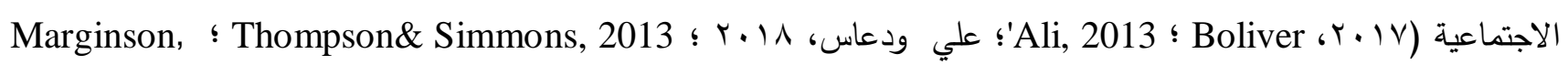
2008 ). ويتوقع أن يصل الأشخاص الذين يحصلون على تعليم عال في البلدان ذات الفرص المتكافئة إلى سلسلة من الإنجازات،

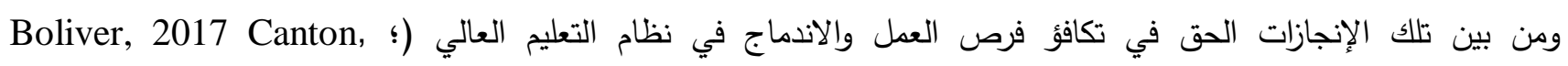

.( Connor, Tyers, Modood \& Hillage, 2004؛ Connor\& Dewson, 2001, ؛ Connor, 2002 ؛ 2002,2003 يعتبر "التعليم العالي" قيمة هامة وأساسية لدى الأقلية العربية في إسرائيل (Arar\& Haj-Yehia,2016 ؛ على ودعاس،

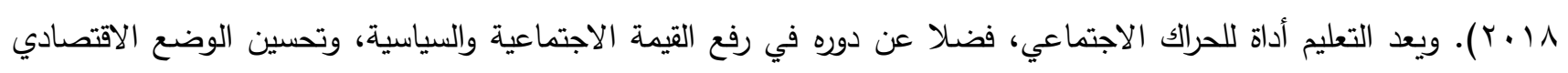

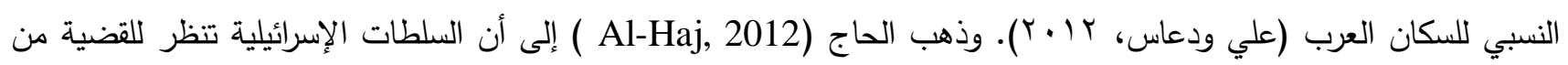

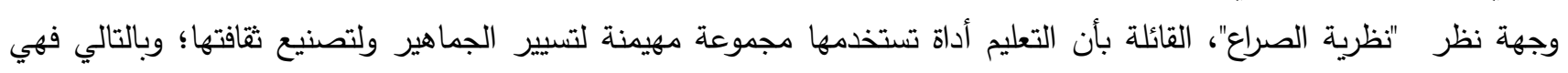

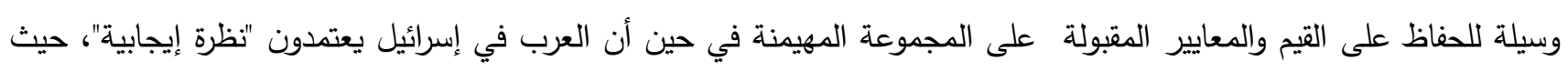

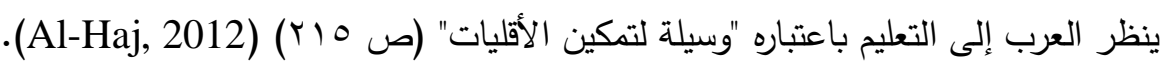

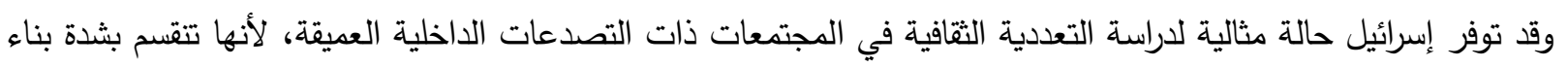

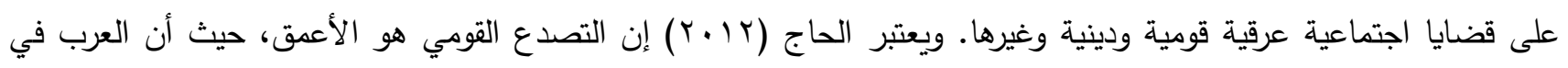

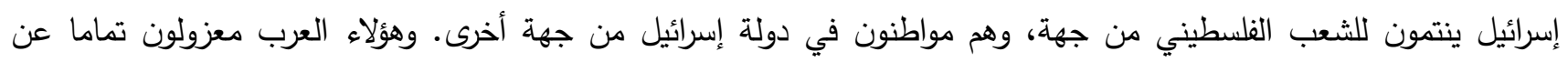

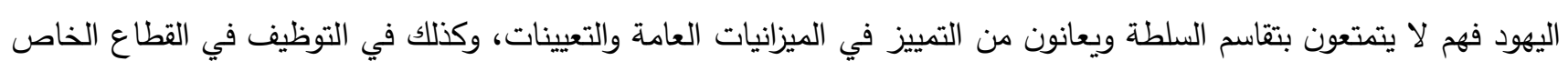

.(Al-Haj, 2012)

تعتبر الأقلية العربية-الفلسطينية في إسرائيل اقلية اصلانية متجذرة لها كيانها المتميز وطنياً- دينياً لغوياً وهو كيانً منفصل عن الاكثرية المسيطرة بشكل واضح المعالم؛ فهم أقلية غير مندمجة ومعارضة لنظام الحكم، وولاءهم للنظام مشكوك فيه من قبل النائ

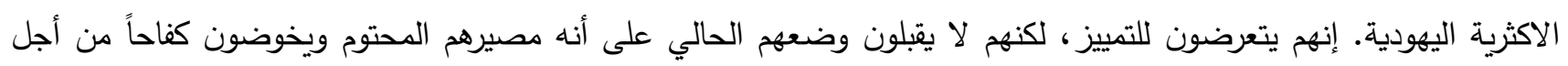

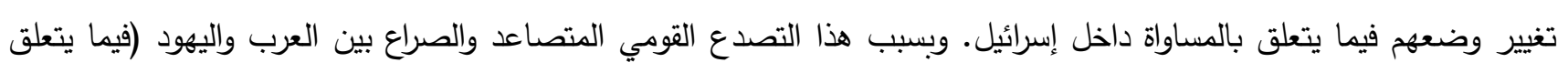

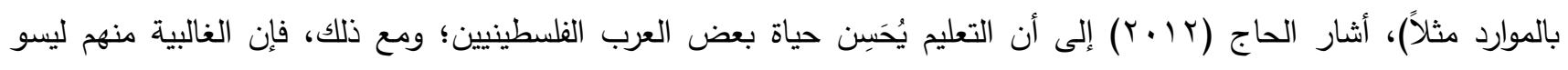
قادرين على التغلب على العقبات واجتياز الحواجز التي تعترض التقدم ومواجهة القصور والنواقص في جهاز التعليم بحد ذاته (.(Haj, 2012

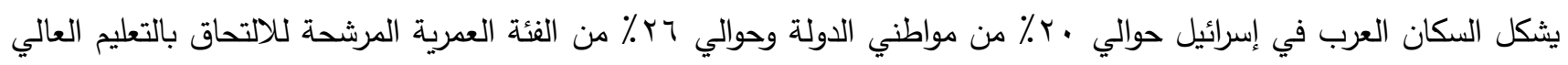

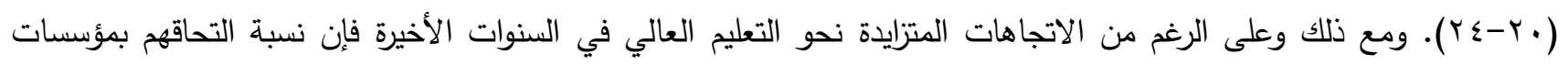

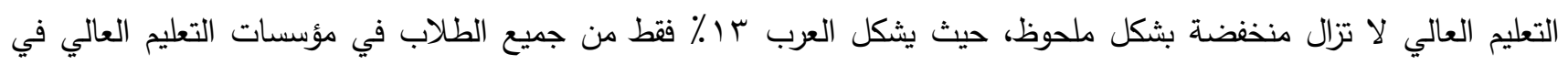

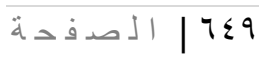




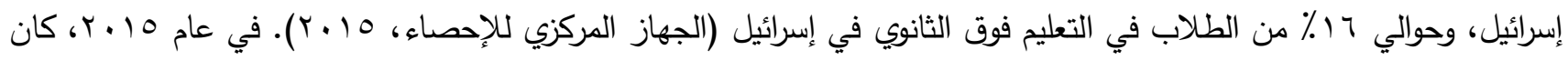

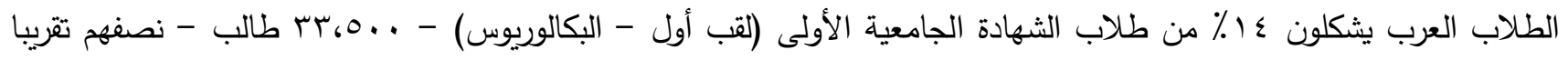

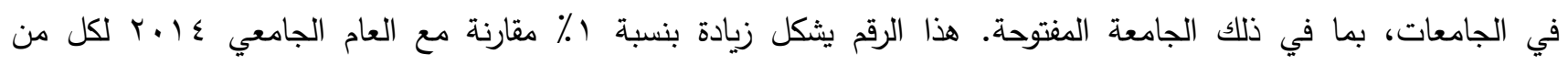

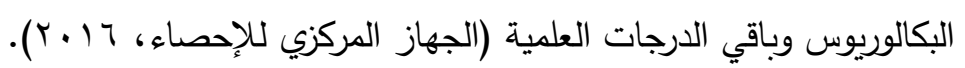

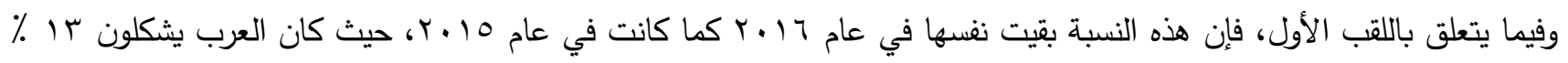

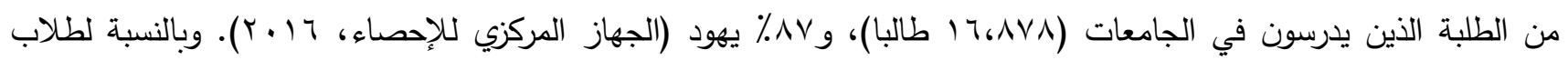

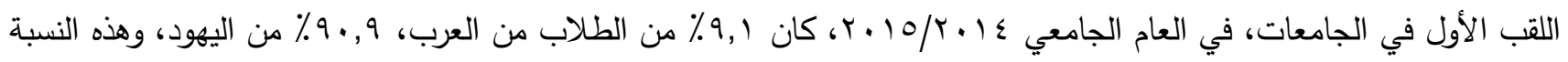

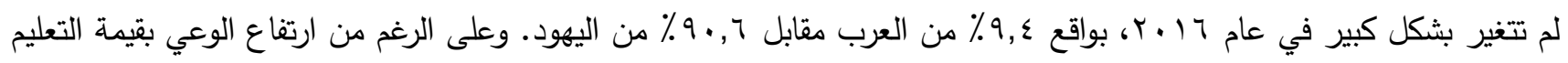

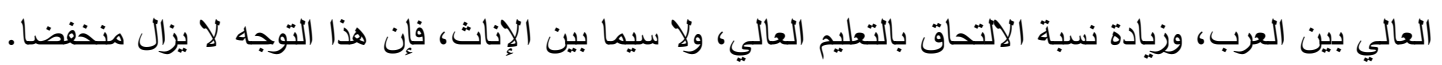

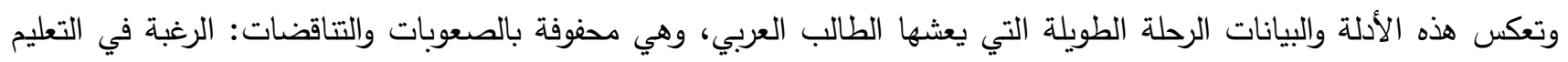
العالي من ناحية، وعدم وجود استجابة مناسبة من مؤسسات التعليم العالي الإسرائيلية للعرب الذين يتقدمون بطلبات التهات التحاق لهذهات

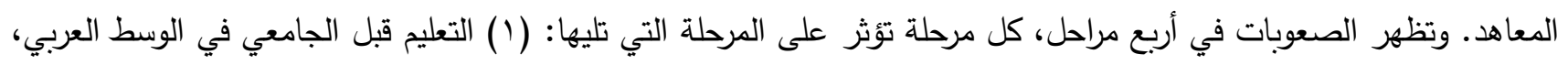

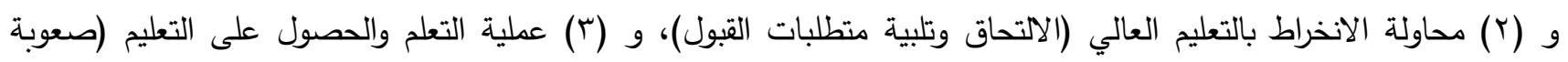

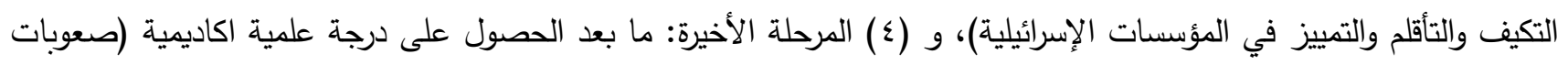
الانخراط في سوق العمل الإسرائيلي). ويمكن الحديث عن ظواهر أخرى في هذه المراحل تميز التعليم العالي بين العرب نتيجة لكل هذه الصعوبات، التي يطلق عليها

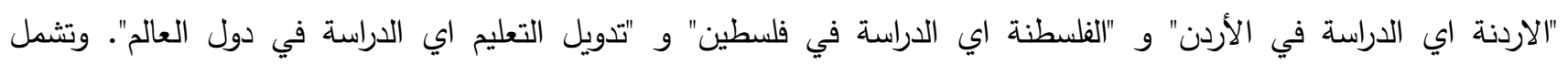
الصعوبات الأخرى في التعليم العالي المعيقات التي يواجهها المحاضرون العرب في الترقية داخل الأوساط الأكاديمية الإسرائيلية

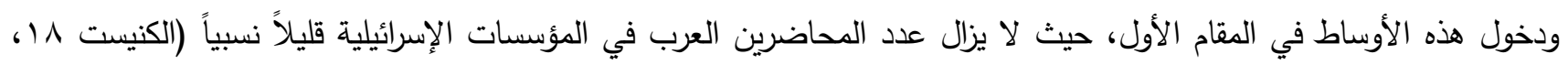

( 'Ali, 2013 ؛ r. 1$)$

ونتيجة لتعقق التصدع القومي واستمرار الصراع على توزيع الموارد، فإننا نرى أن نظام التعليم العالي الإسرائيلي لم يستجب ولم

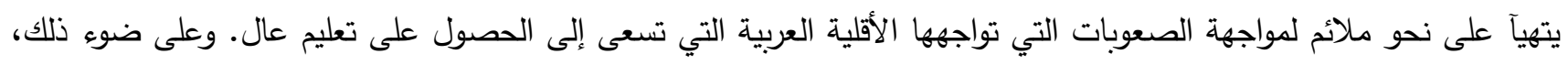

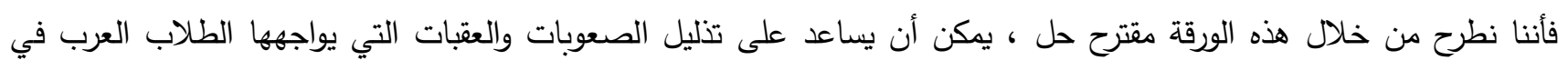
الحصول على شهادة جامعية في إسرائيل. إننا نقترح إنشاء جامعة عربية بحثية. هذا الطرح يمكن أن يكون أيضا بـان بمثابة حل للبطالة

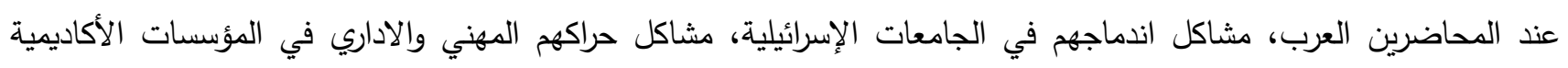

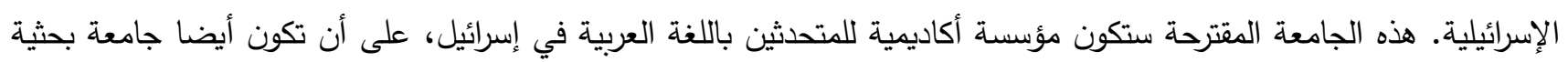
توفر للطلاب العرب المؤهلات اللازمة لتحسين مكانتهم في سوق العمل الإسرائيلي، فضلا عن تأهيل المحاضرين والباحثين العرب.

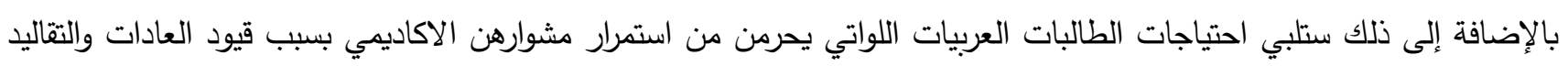

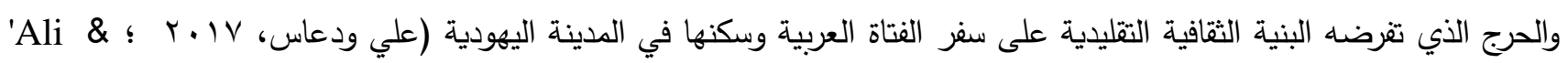

.( Da'as, 2016

في هذه الورقه، سنستعرض أولا العقبات التي يواجهها الطلاب العرب الراغبون في الحصول على التعليم العالي ونقدم أحدث المعطيات حول هذا الموضوع ثم نعرض بتوسع الحل المقترح والعقبات التي تواجه محاولة إنشاء جامعة عربية. 


\section{خلفية تاريخية للأقلية العربية-الفلسطينية في إسرائيل}

إثر قيام دولة إسرائيل، غادرت النخبة السياسية والثقافية والاجتماعية والاقتصادية الفلسطينية أو طردت من بلدها، وكذلك الحال

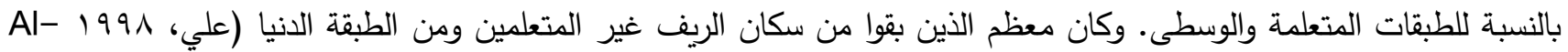
(Haj, 2003, 2012; 'Ali, 2004

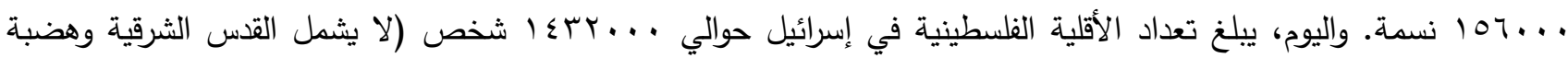

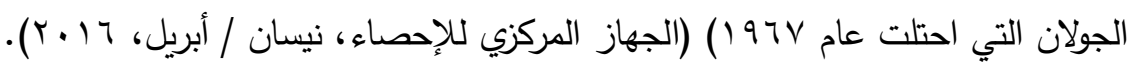

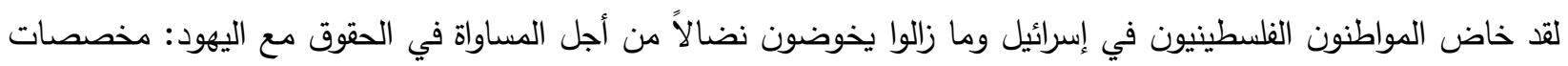
الموارد والأراضي (سياسة الحكومة لتخطيط استخدام الأراضي منحازة بشكل واضح لصالح الأغلبية اليهودية)، وإنشاء المشاريع الاقتصادية وتتمية المناطق الصناعية في مناطق مأهولة بالعرب (لا تستثر الحكومة في هذه المناطق بشكل فعلي). لا تأخذ الحكومة الأقلية العربية واحتياجاتها بعين الاعتبار في توزيع ميزانيات الدولة، ولا سيما ميزانية التعليم، حيث أن أن التمييز

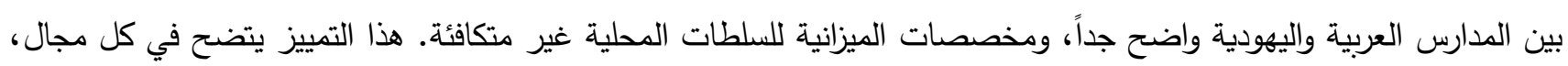

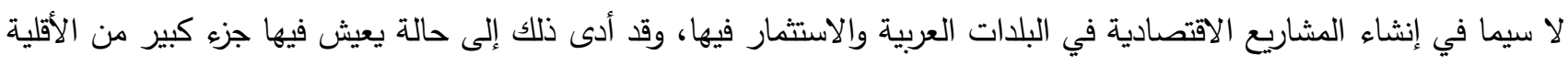
العربية في إسرائيل على حافة الفقر وترتفع بينهم نسبة البطالة ويلاحظ انخفاض مستوى التعليم، ما أدى إلى وجود حالة دائمة من الته

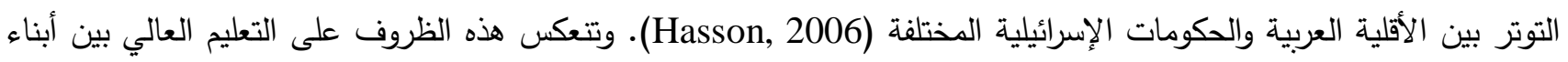
الوسط العربي.

\section{معوقات التعليم العالي في الوسط العربي}

هناك وعي متزايد بين العرب بأهمية التعليم العالي كما يتضح من معدل المتقدمين للدراسة ومعدل الطلاب المقبولين ونسبة الذين

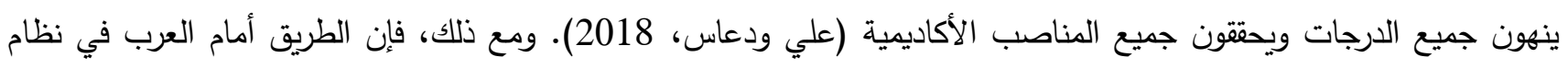

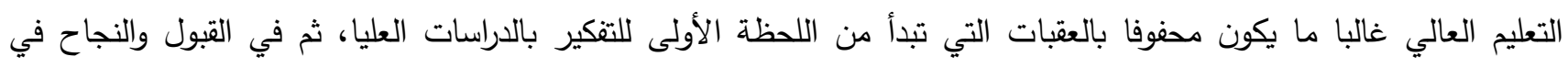

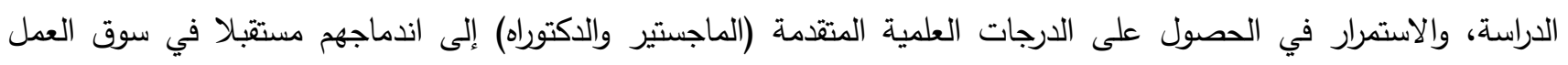
الإسرائيلي في وضع يتتاسب مع تعليمه (علي ودعاس، 2018). وتتاقش هذه العقبات فيما يلي.

أ. نظام التعليم في إسرائيل

تتتمي جميع المدارس في إسرائيل إلى النظام التعليمي الإسرائيلي (أبو عصبة، V . . Y). وتدار المدارس اليهودية من قبل

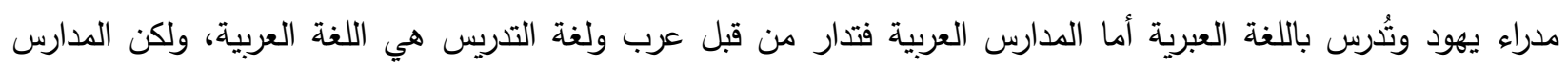

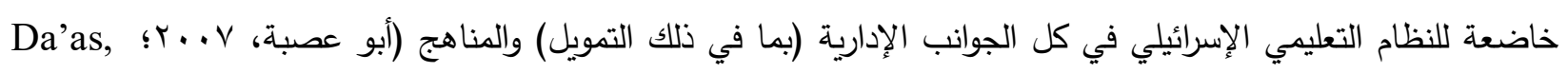

وعلى الرغم من التحسن الذي طرأ على النظام التعليمي في الوسط العربي على مر السنين، إلا أنه يبقى أقل تقدماً من

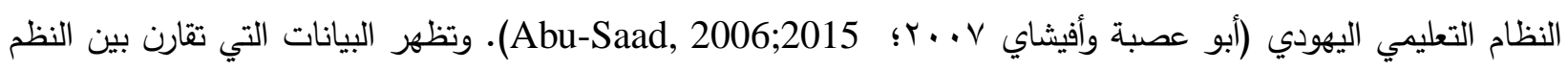
التعليمية العربية واليهودية وجود عدم المساواة في الموارد وتمييز في الميزانيات وتأخر في تطوير برامج التعلم والمحتوى في لني

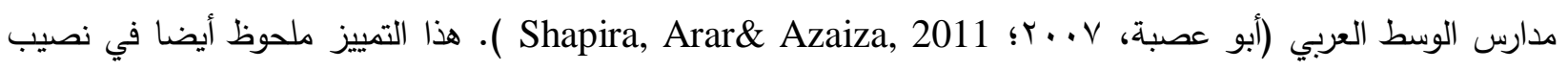
كل طالب من المخصصات، وهناك فجوة كبيرة في المدخلات التعليمية مثل البرامج التي تدعم التلاميذ الضعفاء والمكتبات

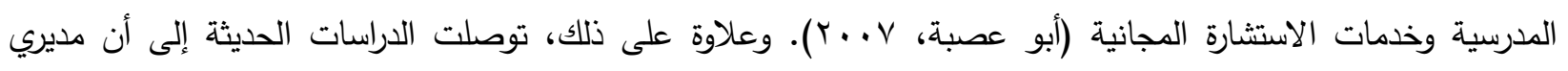

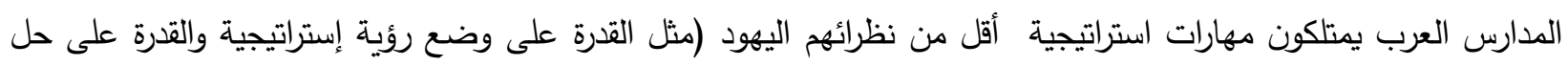

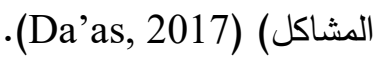


من المتوقع أن تعيق هذه الظروف الحصول على درجات كاملة في امتحانات شهادة القبول في الجامعات (البجروت)، وكذلك فإن معظم المدارس العربية لا تشجع الطلاب على التفكير المستقل أو الناقد وتميل إلى أسلوب التدريس "التلقيني"، حيث يستمع الطالب فقط لما يقوله المعلم ويحفظ المعلومات وبذلك تعد عملية ذهنية غير واعية. تثكل هذه الظروف عائقا كبيرا أمام الطلاب العرب الذين يسعون للحصول على التعليم العالي، ولذلك فإن معلى معدل

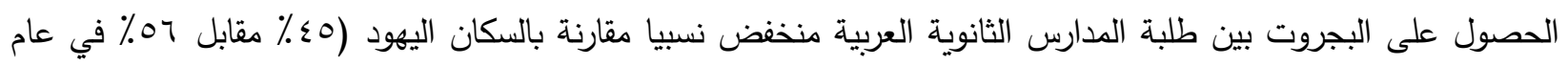

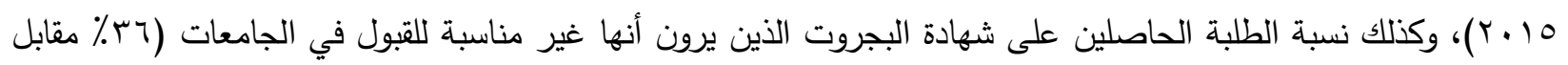

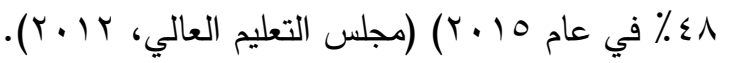

$$
\begin{aligned}
& \text { ب. الوضع الاقتصادي العربي }
\end{aligned}
$$

لم يقم الاقتصاد العربي منذ عام 9 الوفيع الاقلى أساس مبادئ الرأسمالية أو الصناعة، فقد غادرت النخبة العربية السياسية والاقتصادية والطبقة الوسطى البلاد رغماً عنها في معظم الأحيان. وبالتالي اضطر السكان البانئ الباقون إلى الاندماج في الاقتصاد الإسرائيلي من نقطة انطلاق متدنية (Abraham Foundation Initiatives, 2013).

\section{وضع العمالة والفقر}

لا تزال نسبة البطالة في صفوف العرب الفلسطينيين في إسرائيل أعلى بكثير منها بين اليهود، حيث أن معدل المشاركة في

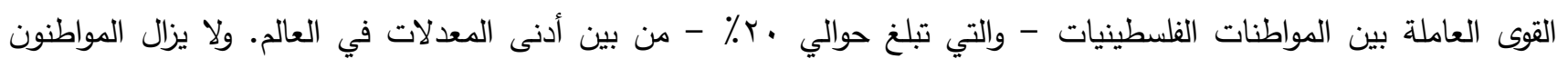
الفلسطينيون في إسرائيل بصفة عامة، والنساء الفلسطينيات بصفة خاصة، يشكلون نسبة منخفضة بشكل غير متكافئ من موظفي

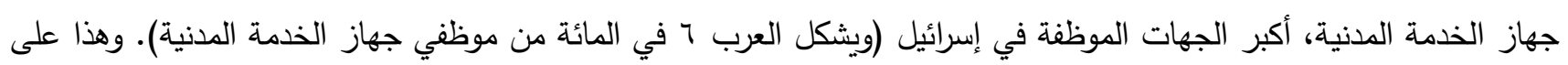

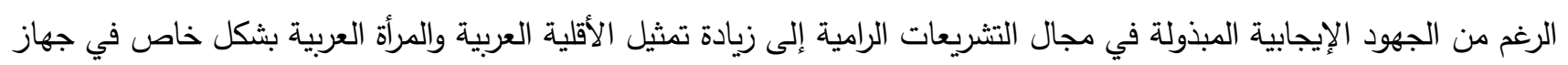

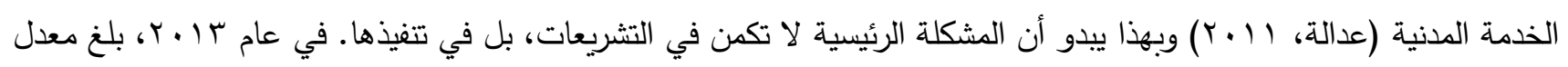

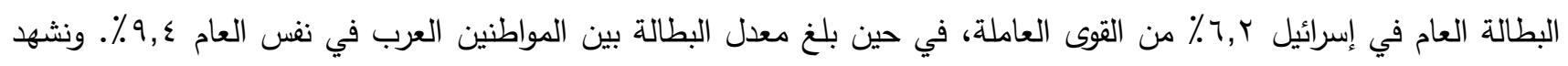

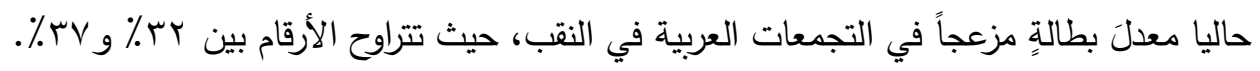

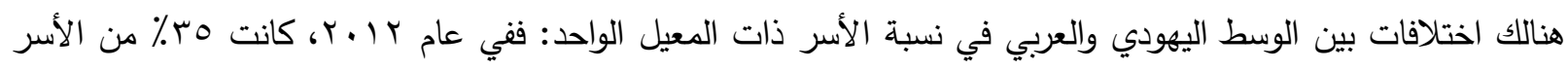

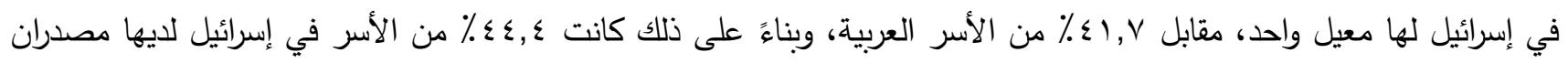

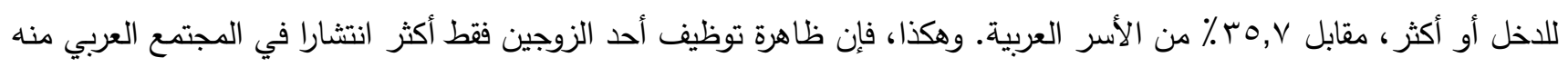

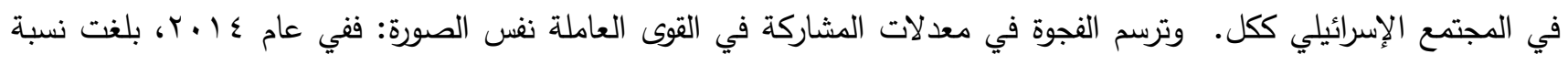

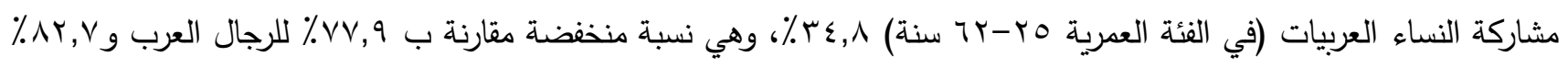

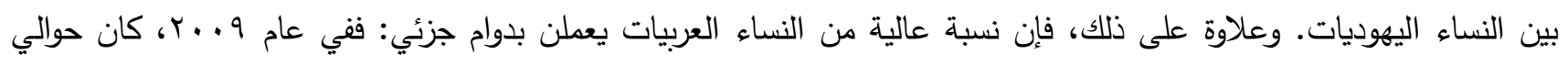

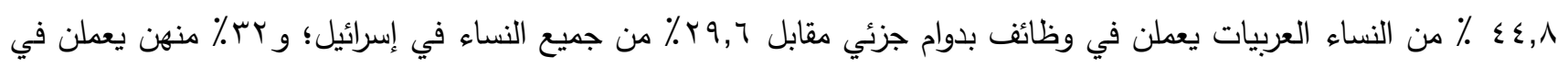
هذه الوظائف رغماً عنهن لعدم وجود بديل.

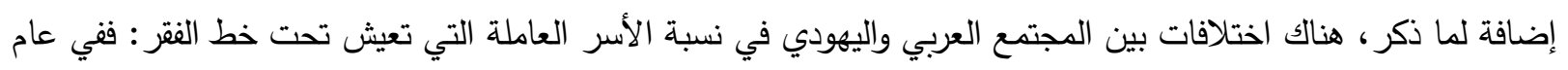

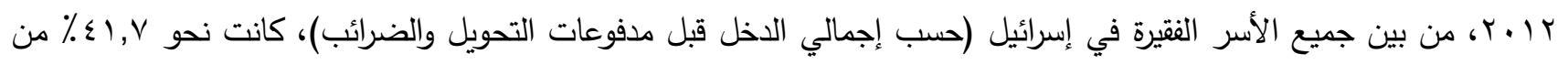

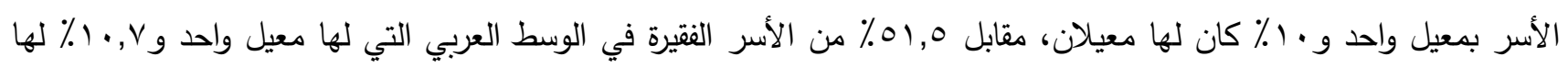

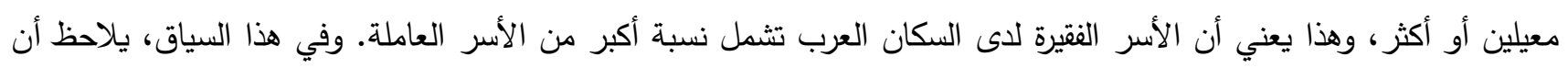

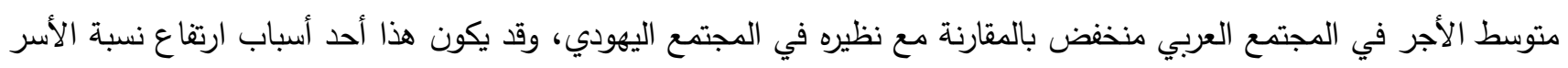
العاملة في المجتمع العربي التي تعيش تحت خط الفقر ( Levy,2015). 
وتجدر الإشارة أيضا إلى أن الرأي القائل بأن معدل المواليد بين المواطنين العرب أعلى من معدل باقي السكان لم يعد يصلح كمبرر

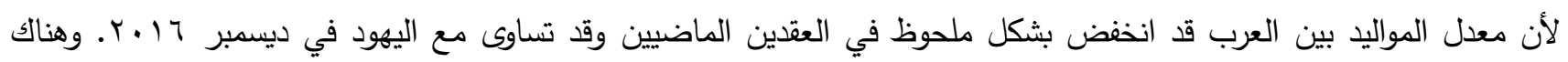

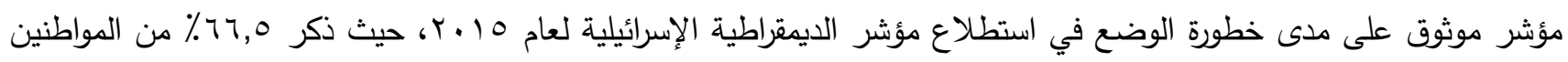

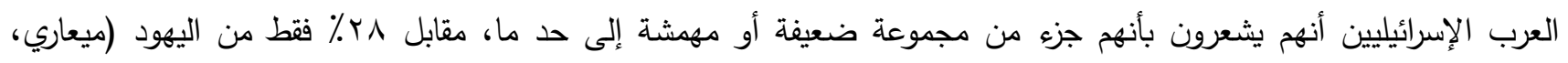

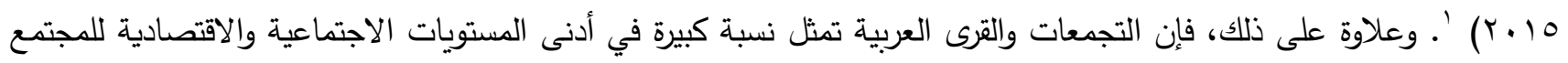

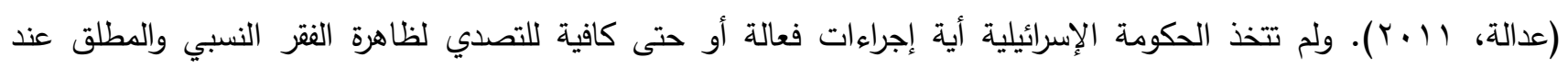
المواطنين العرب-الفلسطينيين في إسرائيل.

وحتى عندما يتم إطلاق مبادرات لخطط تتموية تعود بالفائدة على المجتمع العربي-الفلسطيني، مثل "الخطة المتعددة

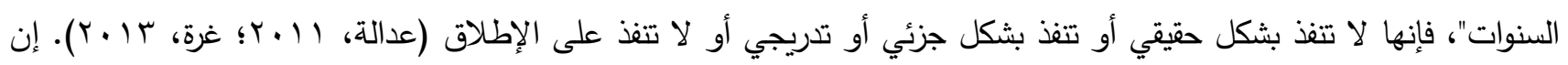

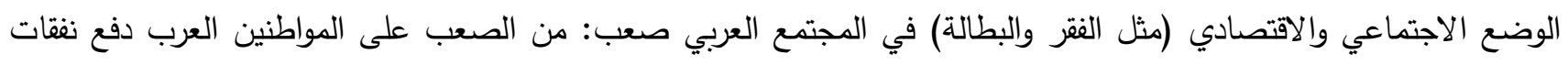
التعليم، وفرصهم قليلة في الحصول على المنح، ويواجهون صعوبة في العثور على وظائف في السوق الخاص للمساعدة في تمويل

\section{نفقات دراستهم. \\ ت. امتحان البسيخومتري}

الدخول إلى الجامعة في إسرائيل مرهون بامتحان البسيخومتري (امتحان القبول للجامعات الإسرائيلية). هذا الامتحان

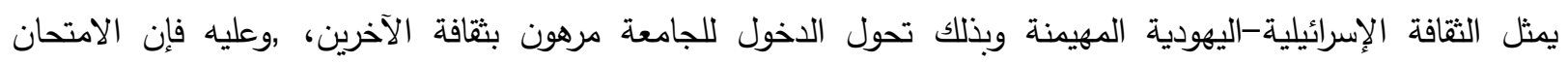

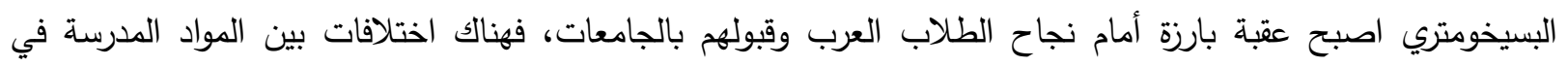

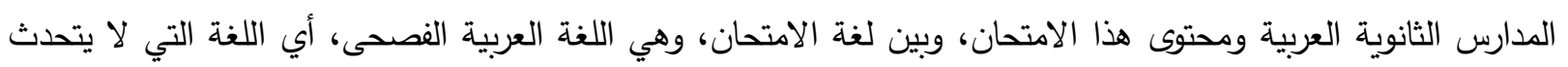
بها الطلاب.

إن امتحان البسيخومتري مصمم بشكل يناسب الثقافة اليهودية الإسرائيلية بشكل خاص، وهو يتضمن مواضيع تدرس

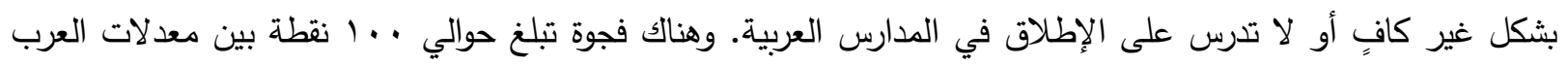
واليهود في هذا الامتحان لصالح اليهود. ونتيجة لذلك، يضطر الطلاب العرب إلى خفض توقعاتهم وعدم دراسة التخصصات التي يطمحون لها مثل الطب أو القانون. وعلاوة على ذلك، فهناك عقبة اللغة حيث يحتوي امتحان البسيخومتري على أجزاء بالعبرية والإنجليزية، وفي المدارس العربية يتم تعلم اللغة العبرية كلغة ثانية واللغة الإنجليزية كلغة ثالثة. هذه العوائق أدت إلى زيادة في نسبة الرفض (عدم القبول للجامعة) من الجامعات في دراسة اللقب الأول (البكالوريوس)

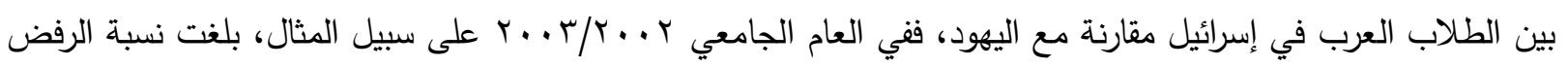

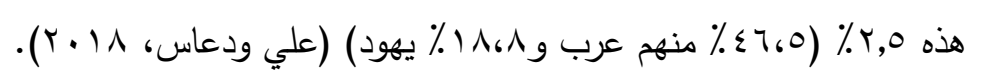

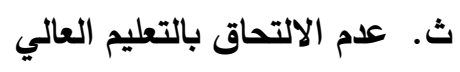

عدم الالتحاق بالتعليم العالي في السنتين الأوليتين بعد الانتهاء من الدراسة الثانوية وضعف الاندماج في المجتمع الإسرائيلي

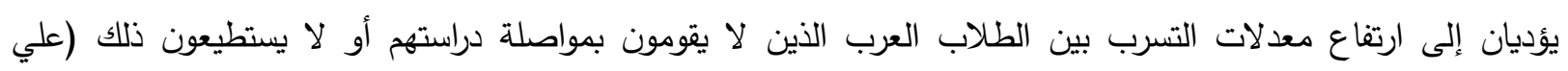

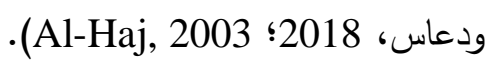

\section{ج. طبيعة الثقافة العربية}

تتميز ثقافة المجتمع العربي بالطابع الجماعي، والهرمية المفهومة ضمناً وأنه مجتمع أبوي ذكوري (Da'as, 2017 ؛ Ali \& Da'as, 2016 '. حيث أن المجال العام ينتمي إلى الرجال ويسيطرون عليه بقبضة حديدية، في حين أن المجال

\footnotetext{
${ }^{1}{ }_{1}$ http://www.idi.org.il/\%D7\%A1\%D7\%A4\%D7\%A8\%D7\%99\%D7\%9D-

9E\%D7\%A8\%D7\%99\%D7\%9D/\%D7\%9E\%D7\%90\%D7\%9E\%D7\%A8\%D7\%99\%D7\%9D/the_arab_poverty
} 
الخاص تسيطر عليه للنساء نوعاً ما (Abu-Hussain, Tilchin, \& ؛'Ali \& Da'as, 2016; Abu- Hussain, 2015

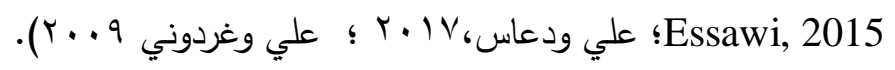

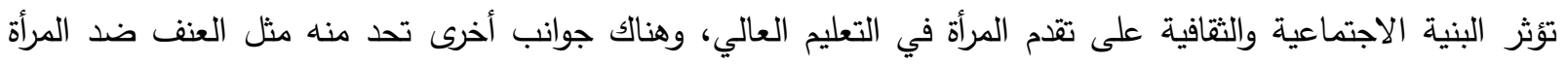

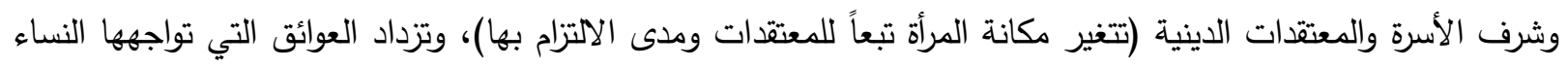
من أسرهن وتتغير خاصة عندما تواجه المرأة ثقافات مختلفة مثل الثقافات الغربية الأخرى (السائدة في معاهد التعليم الإسرائيلية).

\section{جهاز التربية والتعليم العربي تحت السيطرة}

يتكون المجتمع الإسرائيلي من عدة مجتمعات ثانوية غير متجانسة وعلى الرغم من ذلك فان جهاز التعليم فيها ما زال احادي الثقافة وليس متعدد الثقافات (Abu-Saad, 2006؛Al-Haj, 2006 ). منذ العام 9 1، جرت بلورة جهاز التعليم العربي في البلاد وصياغته للأقلية العربية الفلسطينية المتبقية، من خلال المعايير

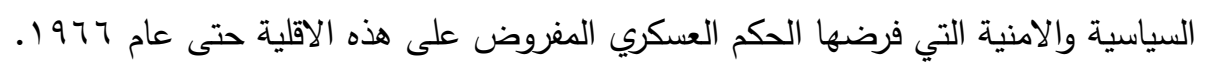

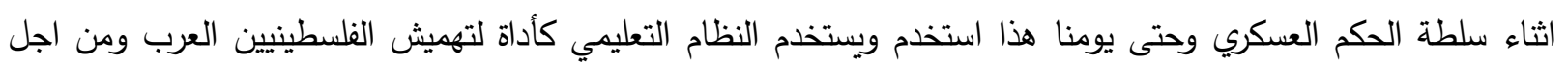
فرض السيطرة عليهم من النواحي الاجتماعية، الاقتصادية والثقافية. وفي مجال التعليم هنالك تمييز واضح ضدي ولد العرب الفلسطينيين في إسرائيل. وينبع التمييز من مشكلتين أساسيتين يعاني منهما التعليم العربي، وهما انعدام الإدارة الذاتية في مجال التعليم والتمييز الفاضح في تخصيص ميزانيات التعليم العربي. فجهاز التعليم العببي يفتقر إلى إدارة ذاتية مستقلة، والمبنى الإداري لهذا لهئي الجهاز يخضع منذ قيام الدولة وحتى اليوم لسيطرة كاملة من قبل الحكومة. حيث أن وزارة التربية والتعليم، وأحيانا جهاز المخابرات (الشاباك) يتحكمون في التعليم العربي في كل المجالات (كالبنية التحتية، ومستوى الخدمات، ومناهج التعليم، والبرامج، والتعيينات). أما

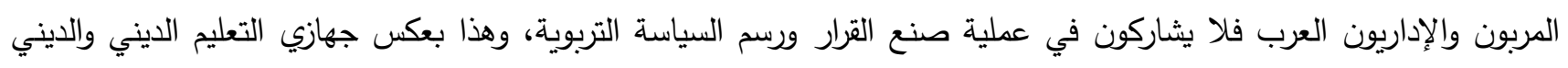

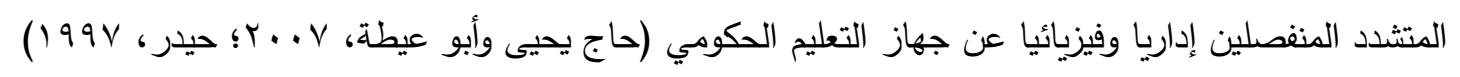

\section{التعليم العالي حسب المعطيات: الوضع الحالي والاتجاهات المستقبلية}

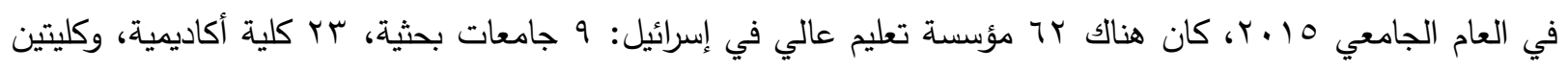
بتمويل من لجنة التخطيط والميزانية، و9 كليات خاصة، و 19 كلية لتدريب المعلمين (مجلس التعليم العالي، لجنة التخطيط والميزانية، 1 ـ ـ ب). ويبين الجدول ( أن عدد طلاب السنة الأولى الذين يدرسون اللقب الأول (البكالوريوس) في الجامعات قد ازداد

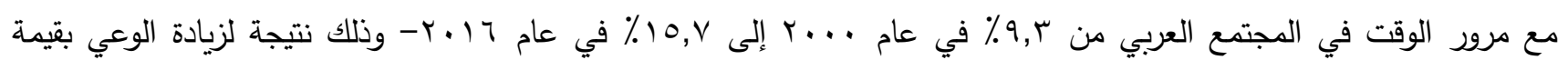

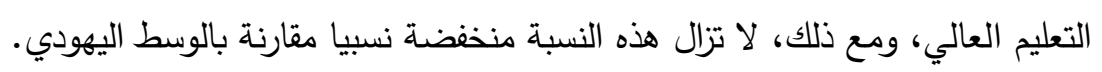

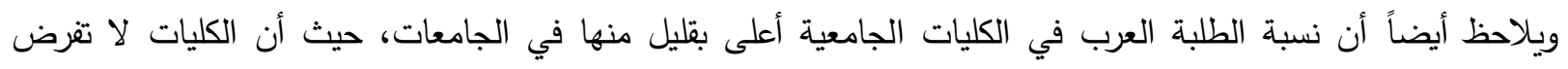
شروطاً كثيرة تحد من قبول الطلبة العرب، مثل شهادة البيسخومتري، ومع ذلك لا يزال عدد الطلاب اليهود المقبولين في ارتفاع كبير •

وعلى الرغم من الزيادة الملحوظة، فإن نسبة الطلبة العرب في صفوف الطلبة الجامعيين في إسرائيل أقل من نصف نسبة

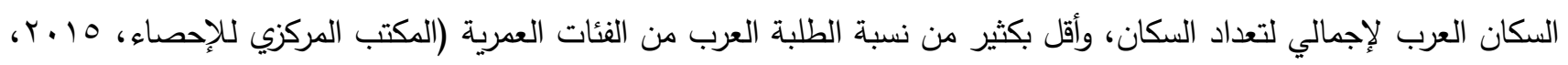

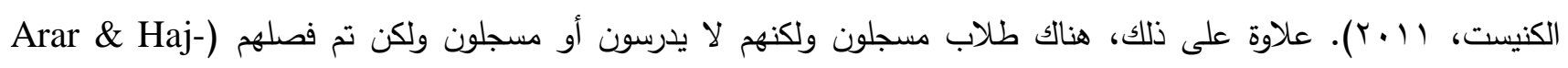

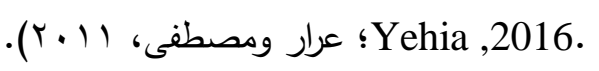


جدول رقم (1): الطلاب في الجامعات، حسب الارجة وإلفئة السكانية والدين ومكان الميلاد

\begin{tabular}{|c|c|c|c|c|c|c|c|c|c|c|c|c|}
\hline \multicolumn{4}{|c|}{ 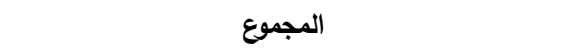 } & \multicolumn{4}{|c|}{ السنه الاولى للقب الاول } & \multicolumn{5}{|c|}{ اللقب الاول } \\
\hline 2015/1 & $2014 / 1$ & $2009 / 1$ & $1999 / 2000$ & $2015 / 1$ & $2014 / 1$ & 2009/1 & $1999 / 20$ & $2015 / 1$ & $2014 / 15$ & 2009/1 & $1999 / 200$ & \\
\hline 6 & 5 & 0 & & 6 & 5 & 0 & 00 & 6 & & 0 & 0 & \\
\hline 129,82 & 132,06 & 123,96 & 112,987 & 23,557 & 23,882 & 23,121 & 22,010 & 78,610 & 80,840 & 75,271 & 74,194 & المجموع \\
\hline 9 & 4 & 4 & & & & & & & & & & \\
\hline 87.0 & 87.4 & 89.6 & 93.0 & 84.3 & 83.5 & 86.4 & 90.7 & 84.5 & 85.0 & 87.2 & 91.4 & يهود \\
\hline & & & & & & & & & & & & واخرون \\
\hline 84.4 & 84.7 & 86.7 & 91.1 & 81.6 & 80.5 & 83.1 & 88.3 & 81.7 & 82.0 & 83.8 & 89.3 & منهم يهود \\
\hline 71.7 & 71.5 & 71.1 & 73.5 & 71.7 & 70.5 & 69.4 & 72.5 & 70.6 & 70.1 & 69.0 & 72.5 & مواليد \\
\hline & & & & & & & & & & & & اسرائيل \\
\hline 12.7 & 13.2 & 15.6 & 17.6 & 9.9 & 10.0 & 13.7 & 15.8 & 11.1 & 11.9 & 14.8 & 16.8 & مواليد ل \\
\hline & & & & & & & & & & & & الخارج \\
\hline 13.0 & 12.6 & 10.4 & 7.0 & 15.7 & 16.5 & 13.6 & 9.3 & 15.5 & 15.0 & 12.8 & 8.6 & عرب \\
\hline 9.1 & 8.8 & 6.8 & 4.4 & 11.3 & 11.8 & 9.0 & 5.9 & 11.0 & 10.6 & 8.3 & 5.3 & منهم \\
\hline & & & & & & & & & & & & 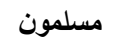 \\
\hline 2.4 & 2.4 & 2.2 & 1.8 & 2.6 & 2.8 & 2.5 & 2.2 & 2.7 & 2.7 & 2.6 & 2.2 & مسيحيون \\
\hline 1.5 & 1.5 & 1.4 & 0.9 & 1.8 & 1.9 & 2.1 & 1.2 & 1.8 & 1.7 & 1.9 & 1.1 & دروز \\
\hline
\end{tabular}

المصدر : المكتب المركزي للاحصاء، Y Y Y P

في الجدول ب يمكننا أن نرى الفجوة بين عدد الطلاب المسجلين في التعليم العالي والطلاب المتقدمين، مما يدل على أنه يتم فصل بعض الطلاب. في الواقع، يمكن للطالب أن يسجل في مؤسسة ومن ثم لا ينظظ في الدراسة، ولكن يجب أن تأخذ إمكانية الفصل

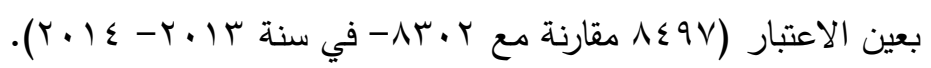

جدول رقم (ץ): عدد الطلبة العرب (أي المرشحين للقبول) في السنة الأولى لدراسة اللقب الأول (البكالوريوس) في الكليات الأكاديمية

\begin{tabular}{|c|c|c|c|c|c|c|}
\hline $\begin{array}{c}\text { تم رفضهج } 2014-2013 \\
\text { ت2013 }\end{array}$ & تم قبولهم لكنهم لم يدرسوا & تم قبولهم ودرسوا & $2012-2013$ & 2009-2010 & 2008-2009 & \\
\hline 8497 & 8302 & 26810 & 50658 & 44459 & 45188 & التسجيلات (أرقام محددة) \\
\hline 5932 & 6637 & 26698 & 45482 & 38936 & 39565 & المرشحين (أرقام محددة) \\
\hline 14.1 & 16.5 & 69.4 & 85.7 & 87.9 & 88.3 & اليهود (النسب المئوية) \\
\hline 20.2 & 19.4 & 60.4 & 10.7 & 8.4 & 8.1 & العرب (النسب المئوية) \\
\hline
\end{tabular}

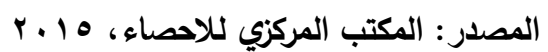

ويعرض الجدول r النسب المئوية المقلقة للطلاب العرب في المؤسسات الأكاديمية الإسرائيلية. 1,ـ (٪ فقط من الطلاب العرب قد

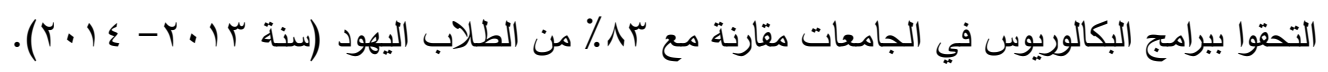


جدول رقم (ץ): نسبة طلبة الجامعات، الكليات وكلية التربية نسبة الى السكان

\begin{tabular}{|c|c|c|c|c|c|c|}
\hline الجامعات & الجامعات & الجامعات & الجامعات & الكليات الأكاديمية & الكليات الأكاديمية للتربية & \\
\hline 159933 & 184851 & 196666 & 82519 & 86377 & 28922 & (أرقام محددة ) \\
\hline 88.9 & 85.0 & 84.2 & 83.0 & 87.4 & 74.4 & 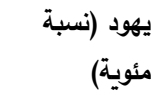 \\
\hline 8.4 & 11.9 & 12.9 & 14.1 & 9.0 & 24.9 & 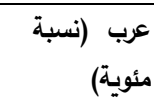 \\
\hline 38855 & 47237 & 54465 & 39525 & 10550 & 4663 & (أرقام محددة ) \\
\hline 93.0 & 91.1 & 88.9 & 89.3 & 90.1 & 73.9 & يهود \\
\hline 5.2 & 6.9 & 9.2 & 8.8 & 8.0 & 25.5 & عرب \\
\hline 9315 & 10567 & 10655 & & & & 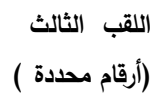 \\
\hline 94.3 & 93.6 & 92.6 & & & & يهود \\
\hline 3.4 & 4.0 & 4.9 & & & & عرب \\
\hline
\end{tabular}

المصدر: المكتب المركزي للاحصاء ه + ب

يبرز الفرق بين العرب واليهود أيضا في اختيار التخصصات، فالعرب يدرسون بعض المواضيع أكثر من غيرها، مثل العلوم الإنسانية والعلوم الاجتماعية، مما يحد أيضا من قدرتهم على دخول سوق العمل (لمزيد من التفاصيل، انظر الجهاز المركزي

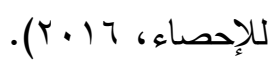

أ. أمحاضرون الأكاديميون

إن الوضع في التعليم العالي أكثر سوءاً عندما يأخذ المرء في الاعتبار الأكاديميين (المحاضرين) وأعضاء الهيئة الإدارية في

الجامعات. ويبين الجدول ع نسبة أعضاء هيئة التدريس العرب في المؤسسات الإسرائيلية.

\begin{tabular}{|c|c|c|c|}
\hline \multicolumn{3}{|c|}{ الكادر الأكاديمي } & \multirow[b]{2}{*}{ الاكاديمية } \\
\hline المجموع & يهود & عرب & \\
\hline $592(100 \%)$ & $569(96.1 \%)$ & $23(3.9 \%)$ & جامعة حيفا \\
\hline $559(100 \%)$ & $552(98.75 \%)$ & $7(1.25 \%)$ & التفنيون \\
\hline 937 (100\%) & 923 (98.5\%) & $14(1.5 \%)$ & جامعة تل ابيب \\
\hline $662(100 \%)$ & 660 (99.7\%) & $2(0.3) \%$ & بار ايلان \\
\hline $825(100 \%)$ & 800 (97\%) & $25(3 \%)$ & جامعة بن غوريون \\
\hline $1010(100 \%)$ & 1000 (99.1\%) & $10(0.99 \%)$ & الجامعة العبرية \\
\hline $80(100 \%)$ & $79(98.75 \%)$ & $1(1.25 \%)$ & الجامعة المفتوحة \\
\hline $4,665(100 \%)$ & $4,583(98.25 \%)$ & $82(1.75 \%)$ & المجموع \\
\hline
\end{tabular}




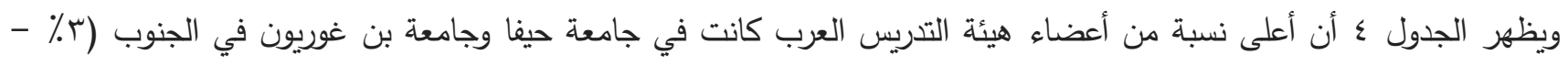
9, ؟\%)، وحتى في هذه الجامعات فإن نسبة المحاضرين العرب ليست مرتفعة. وبالمقابل، كانت أقل نسبة من أعضاء هيئة التدريس

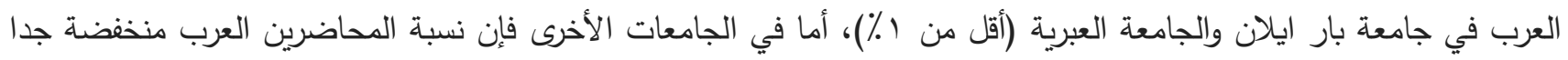
أو هامشية (1\% - (1). (1).

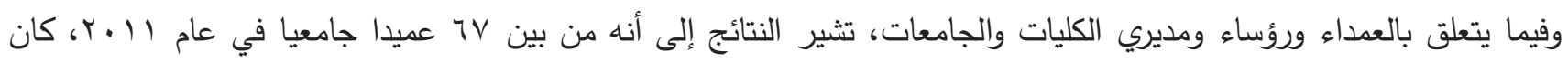
هناك أستاذ عربي واحد فقط (الأستاذ الدكتور ماجد الحاج، عميد البحث في جامعة حيفا) وقد غادر هذاء المنصب وندي منذ ذلك الحين. في عام 17 ـ ب، تم تعيين البروفيسور فيصل عزايزة عميدا لكلية العلوم الصحية في جامعة حيفا والبروفيسور ميخائيل كريني عميدا

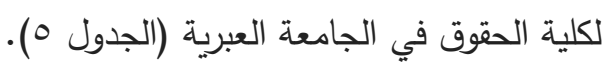

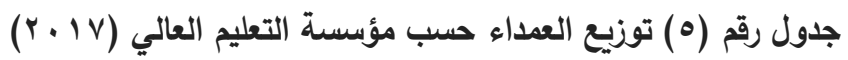

\begin{tabular}{|c|c|c|}
\hline عرب & يهود & عداء الكليات حسب المؤسسة التعليمية \\
\hline 1 & 8 & جامعة حيفا \\
\hline 0 & 17 & التخنيون \\
\hline 0 & 11 & جامعة تل ابيب \\
\hline 0 & 10 & بار ايلان \\
\hline 0 & 8 & جامعة بن غوريون \\
\hline 1 & 10 & الجامعة العبرية \\
\hline 0 & 3 & الجامعة المفتوحة \\
\hline 0 & 6 & 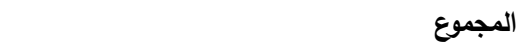 \\
\hline
\end{tabular}

وفي العقد الماضي، كانت هناك جهود على شكل تمويل/منح دراسية من قبل مجلس التعليم العالي ولجنة التخطيط والميزانية

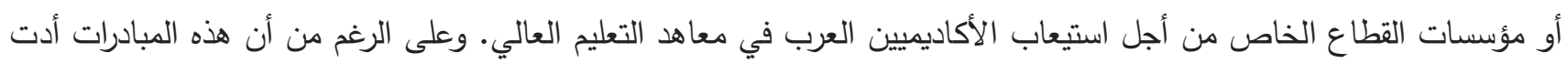

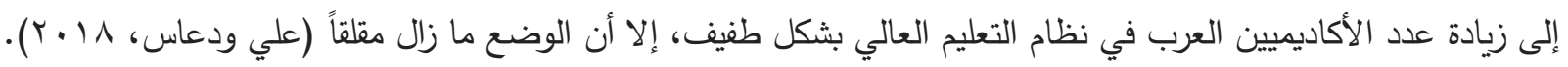

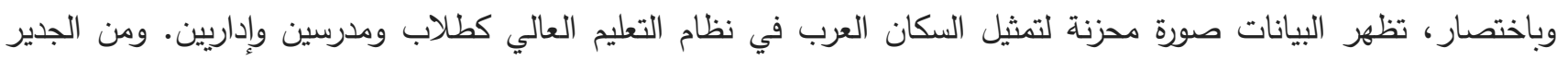

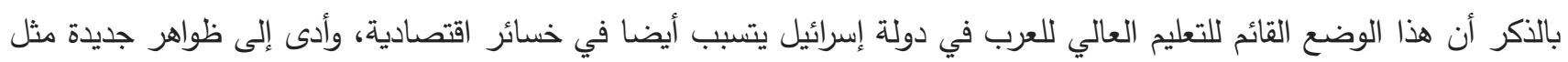

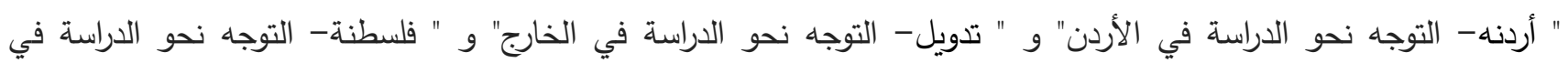
فلسطين". وهي جزء من الرحلة المتعبة للتعليم العالي بين الطلبة العرب. وعلى الرغم من الارتفاع الكبير في نسبة الطلاب العرب الذين

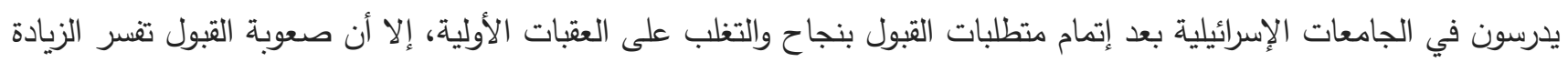

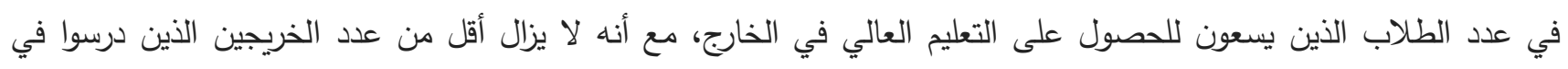

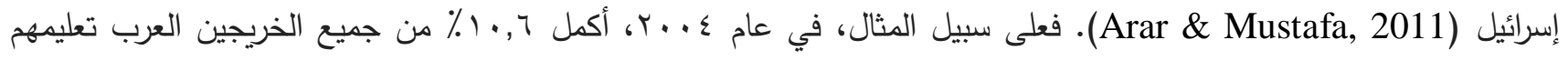

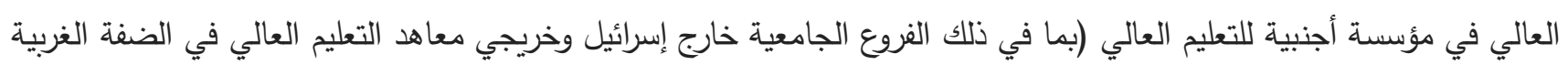

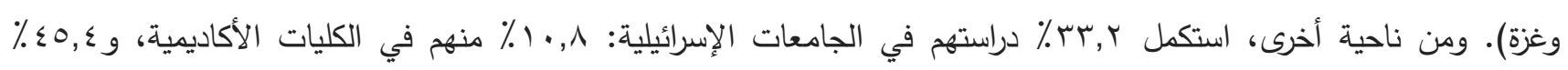

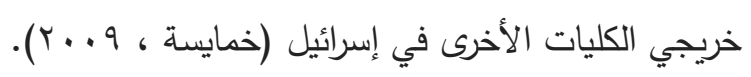

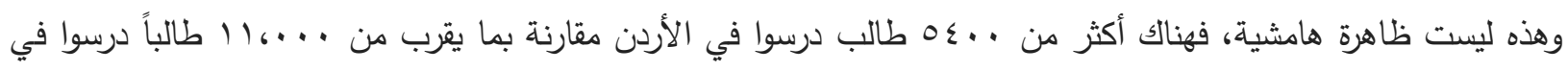

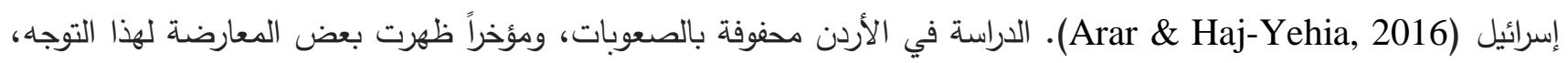

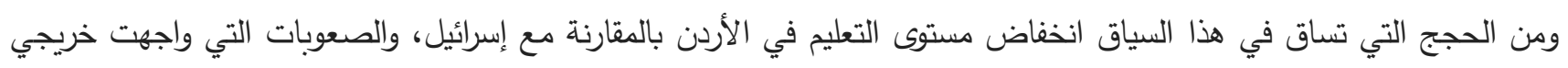




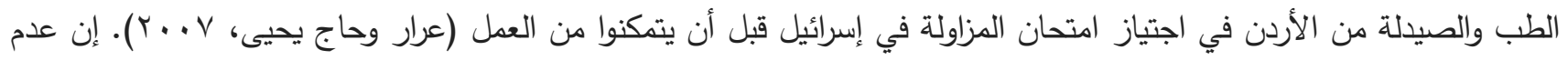
وجود أي نوع من التخطيط أو السياسات الموجهة للتطوير الأكاديمي بين العرب في إسرائيل يشير الثكوك حول ما إذا كانت الثران الدراسة

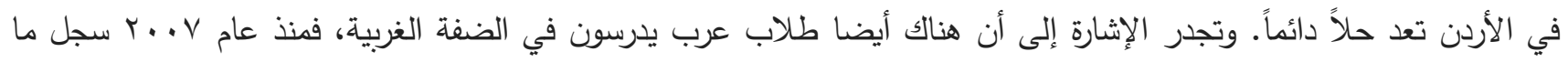

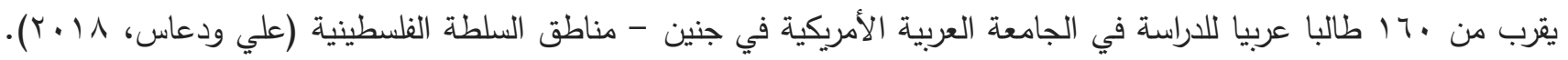
وفي عام ^ . . r، بلغ عدد الطلاب العرب الإسرائيليين الذين يدرسون في جنين حوالي . . ب طالب درسوا الطب والمهن الطبية التي لم يقبلوا لدراستها في الجامعات الإسرائيلية (Arar \& Haj-Yehia, 2013). الدراسة في الخارج ليست خالية من المشاكل. وكثير ما اشتكى الطلاب من الأقليات باستمرار من المزيد من المعاناة من التجارب السلبية في الحرم الجامعي. وعلى وجه الخصوص، فإنهم يواجهون المزيد من العداء والعنصرية والأفكار المسبقة والمزيد من الضغوط على "التمسك بالقوالب النمطية" من المجموعات الأخرى (Ancis, Sedlacek, \& Mohr, 2000 ) . وعلى المستوى ولأن الاجتماعي، يشعر الطلاب المنحدرين من الأقليات بأنهم غرباء لأن المؤسسة الجامعية تضطهد ثقافتهم. ويلاحظون الفصل الثقافي

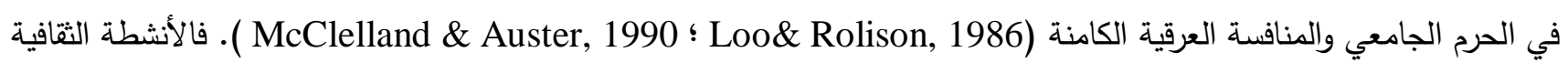
في الحرم الجامعي تمثل ثقافة الغالبية وترعاها، بينما لا تحظى ثقافة الأقليات بأي اهتمام. وقد أدى هذا الاحساس إلى مشاعر من

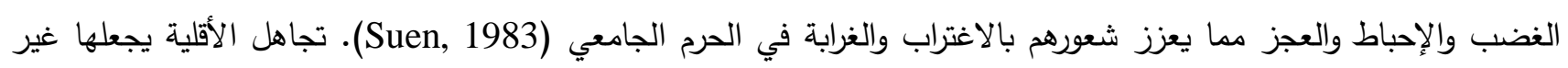

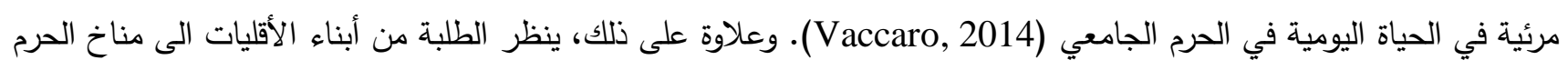

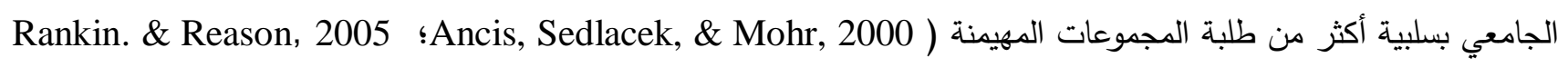

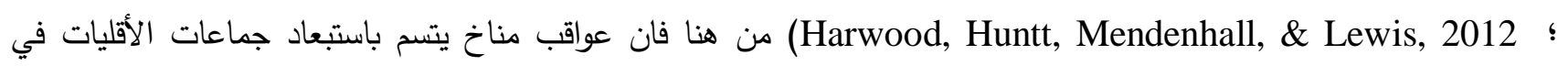

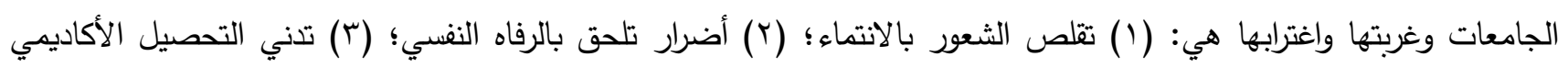

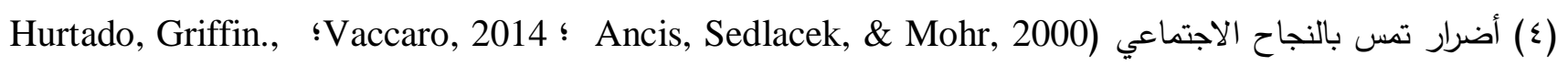
Arellano\& Cuellar, 2008 ) وعلاوة على ذلك، أفاد الباحثون بأن عواقب هذا المناخ تتعكس في معدل تسرب ابناء الأقليات من البيئة التي تتسم بهكذا تمييز ، بسبب العلاقات العدائية والتمييزية، ونقص الدعم الأكاديمي والاجتماعي، وعدم الثعور بالانتماء (على سبيل المثال، Back, من البئة). وباختصار ، فإن تطوير التعليم العالي في إسرائيل لم يعتبر الأقلية العربية كجزء من حركته نحو التغيير، سواء في التوسع في عمليات التعليم العالي وإمكانية الوصول إلى السكان المحيطين، أو عملية خصخصتها أو استيعابها الداخلي (علي ودعاس، لعاسئ .$(2018$

فقد تأسست الأوساط الأكاديمية في إسرائيل على الروح اليهودية الصهيونية، التي لا تعتبر العرب جزءا منها، وتبقى هامشية

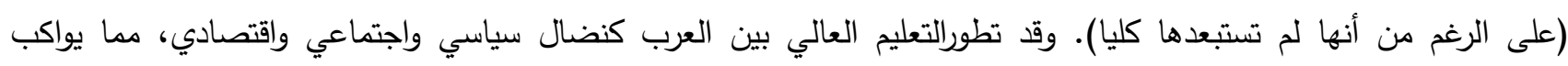
التغيرات الاجتماعية والتعليمية التي حدثت في السنوات الأخيرة (Abu-Rabia-Queder \& Arar,2011).

\section{إنشاء جامعة عربية في إسرائيل: التحديات والعقبات والإحتمالات}

لقد كان لتهميش الطلبة العرب والتمييز ضدهم فيما يتعلق بسياسات الالتحاق بمؤسسات التعليم العالي في إسرائيل، أثر أثر

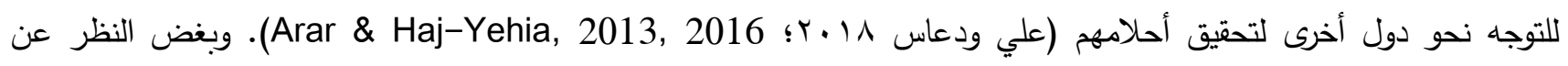

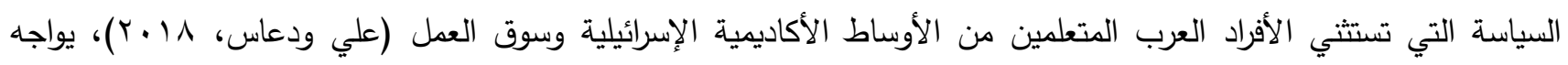

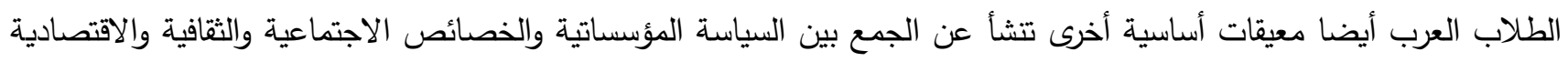
في المجتمع العربي، مع عدم وجود موارد لنظام التعليم العربي في إسرائيل في مرحلة ما قبل الجامعة.

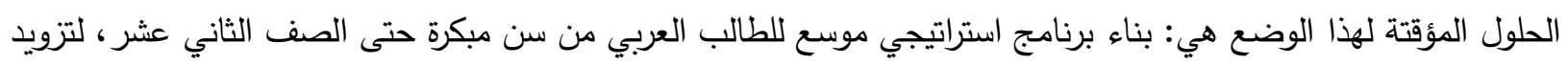

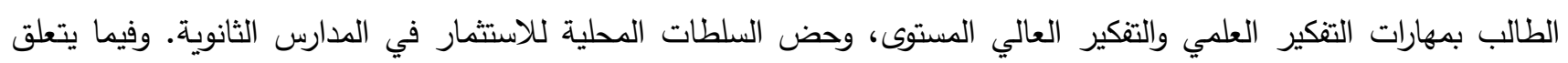


بالموارد المادية، يجب على الدولة تخصيص المزيد من المنح الدراسية والأموال للطلبة العرب، ولا سيما أولئك الذين يواجهون عقبات

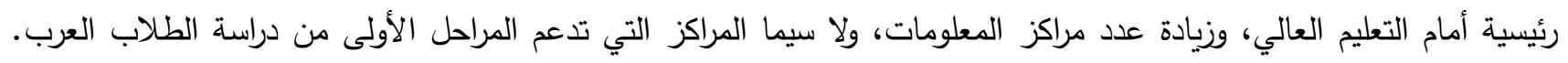

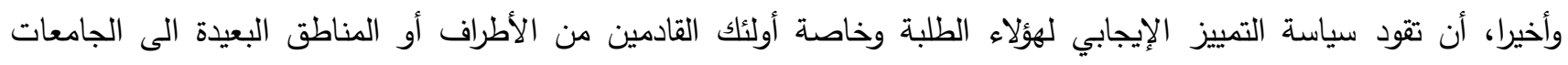
الإسرائيلية، من خلال تأمين الحد الأدنى من الأماكن والبرامج الإرشادية المناءية وخية.

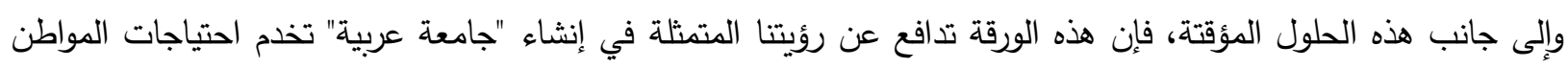
العربي والطالب والمحاضر ، وفي الواقع فأنها تخدم المجتمع ككل. وستحافظ هذه الجامعة على المعايير الأكاديمية الغربية مع مراعاة

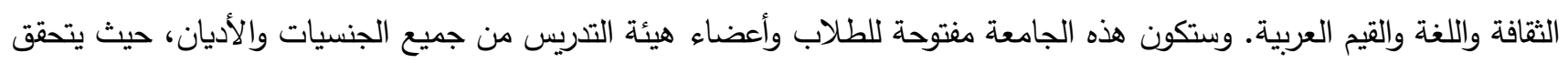

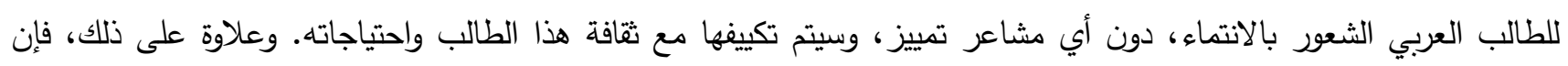
هذه الجامعة سوف تقلل من ظاهرة تسرب الطلاب العرب بسبب العقبات الاجتماعية، وسوف تحد من الثعور بالاغتراب بين الطلاب العرب، والتكيف القسري للثقافة الفردية الغربية التي تختلف عن تلك المتجذرة في المجتمع العربي (وهذه الأمورهي خاصدة

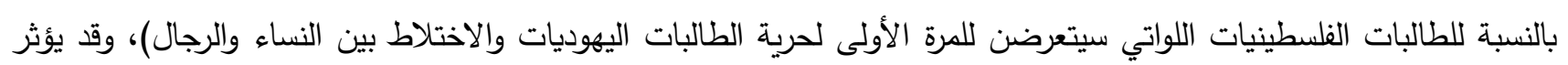
العدد المتزايد من الطلاب العرب الذين يدرسون في الأردن ومناطق السلطة الفلسطينية في المستقبل القريب، في تطوير التعليم العالي بين العرب في إسرائيل. وبناء على ذلك، هناك حاجة إلى سياسة جديدة لزيادة عدد العرب المتعلمين وتسهيل حياتهم.

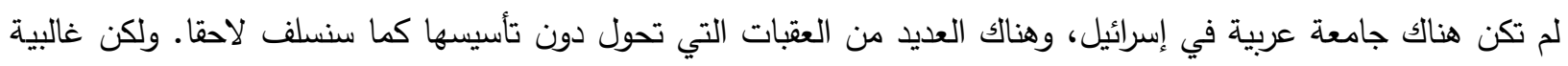

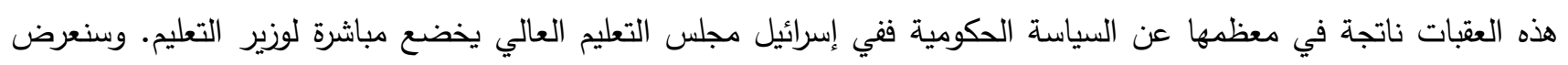
فيما يلي العقبات الرئيسية التي حالت دون انشاء جامعة فئات عربية في اسرائيل.

\section{إنشاء جامعة عربية في إسرائيل: الحواجز والعقبات}

منذ التسعينيات، أضيفت العديد من الجامعات والكليات ومعاهد التعليم العالي إلى نظام التعليم الوطني، ولكن لم يكن لدى الى إلى إحدى هذه المؤسسات محاضرين يحاضرون باللغة العربية، ولم توجد جامعة عربية. وعلاوة على ذلك، فإن الصعوبات التي تواجه

الطلاب العرب لم يتم الحد منها.

وكان إنشاء جامعة عربية وما زال مطلبا مهما من القادة العرب في إسرائيل. وأظهرت إحدى الدراسات الاستقصائية أن ثلاثة

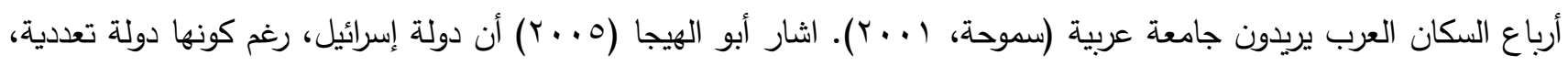

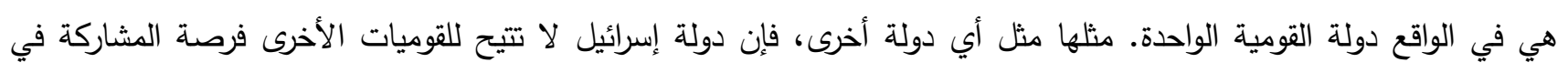

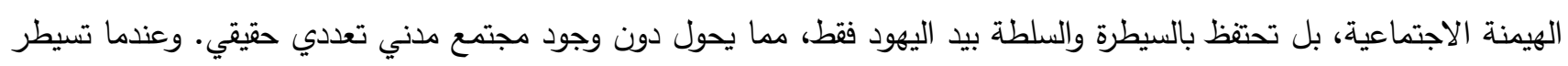

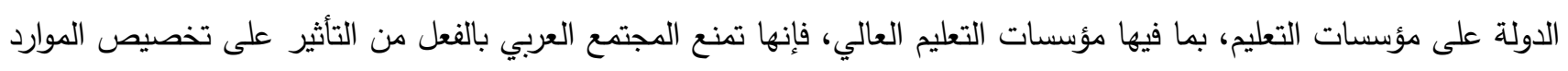

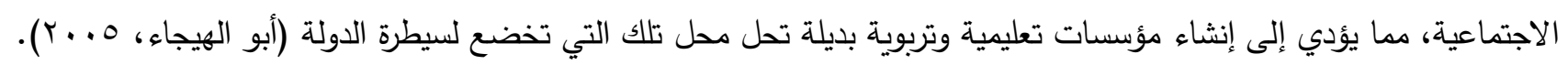

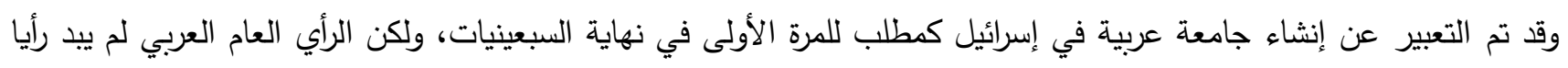

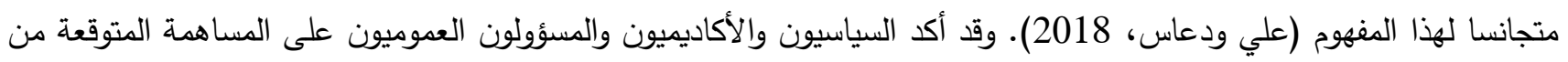

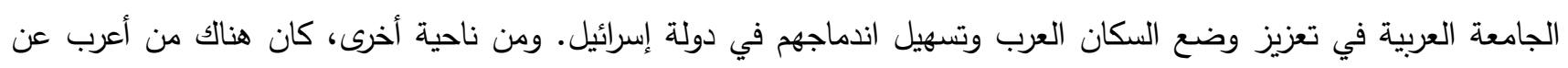

مخاوفه من أن هذا المشروع قد يعرقل تقدم (أو النهوض بمستوى) المواطنين العرب في إسرائيل وذلك يسبب العزلة (فرح، و9 99 ( ). هناك عاملان رئيسيان لهما دور مهم في افشال إنشاء جامعة عربية في إسرائيل. الأول هو مواقف الحكومة ومجلس التعليم العالي. والحجة الرئيسية للمسؤولين الحكوميين هي الأمن القومي: الخوف من أن تكون هذه الجامعة معقل للمقاومة السياسية. وعلاوة على ذلك، هناك خوف من أن الطلب على إنثاء جامعة عربية سيقود للمطالبة بالاستقلال الثقافي، وربما حتى الحكم الذاتي لئي

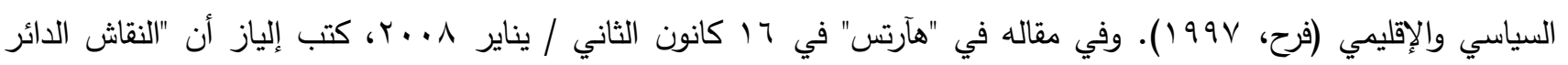
والمتعلق بضرورة وإمكانية انشاء جامعة عربية كان قد بدأ بالفعل في أوائل العشرينيات من القرن الماضي، فالوني عندما اعتبرت سلطات 
الانتداب البريطانية اقتراحا أثاره العرب في تلك الأيام ". بعد بضعة عقود تم اخذ الفكرة بعين الاعتبار من قبل وزير التعليم الاسبق

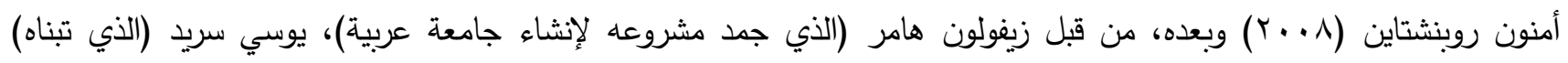

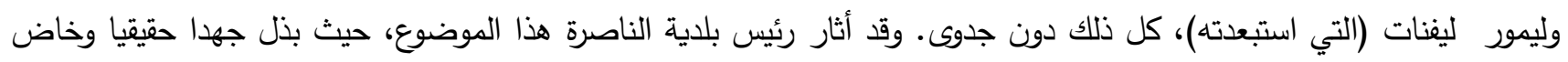

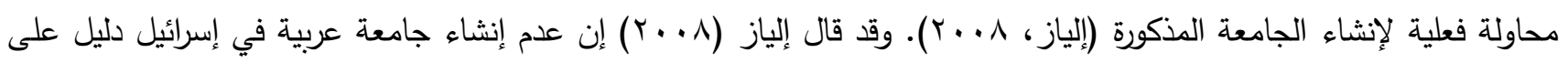
استمرار التمييز ضد المواطنين العرب الإسرائيليين في مجال التعليم كما هو الحال في المجالات الأخرى، وقال إن إنشاء مثل هذهاء إنهاء الجامعة من شأنه أن يقلل من الفجوات ويعزز المساواة ليس فقط في مجال التعليم الأكاديمي، ولكن في مجالات أخرى أيضا، مثل:

$$
\text { الأدب والمسرح، وغيرها. }
$$

وعلاوة على ذلك، طرحت مسألة إنشاء جامعة عربية في إسرائيل عدة مرات للمناقشة من قبل الكنيست بكامل هيئتها، من قبل أعضاء الكنيست العرب من مختلف الأحزاب السياسية. وقد أبدى أعضاء الكنيست عددا من الاقتراحات على جداول الأعمال وقدموها، مما أثار حججا قوية ضدهم من قبل أعضاء الكنيست اليهود، معظمه من الأحزاب اليمينية. ورأى المبادرون أن هذه اعنه الجامعة هي مطلب شرعي للأقلية العربية وأنه لا يوجد سبب منطقي لمنعهم من إنشاء هكذا مؤسسة تعليمية، ناهيك عن حقيقة أن أن هذا المشروع من شأنه أن يزيد من إمكانية حصول العرب الإسرائيليين على التعليم العالي وبالتالي تعزيز مكانتهم واندماجهم

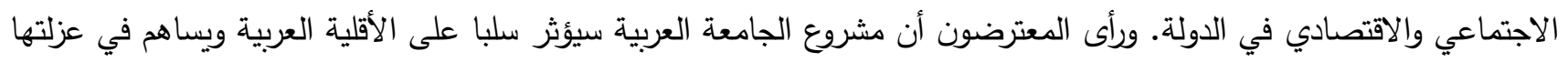

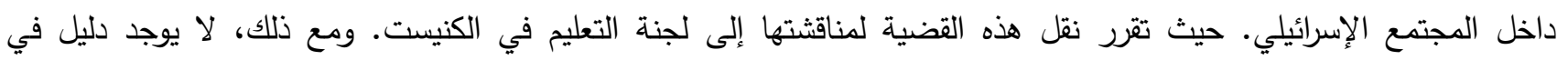
السجلات على إجراء مثل هذه المناقثة بشكل جدي. ولا يزال تأثير أعضاء الكنيست العرب ومشاركتهم في هذه القضية محدودا وهامشيا.

وظهرت الاعتراضات (وحتى المقاومة) من مجلس التعليم العالي أيضا. فقد أكد الوزير يوسي سريد في اجتماع لجنة المتابعة

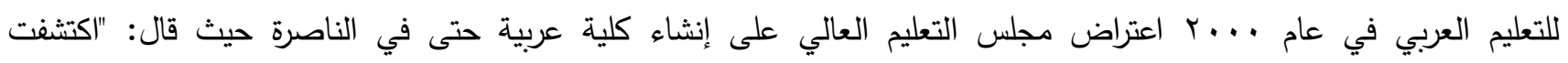
الاعتراض في مجلس التعليم العالي على اقامة كلية عربية وطلبت تشكيل فريق من المهنيين، ومعظمهم من العرب، من أجل إنشاء كلية في الناصرة "(سريد، .... ب). ويتجلى دليل على هذا الوضح في رد ليمور ليفنات على نبيه أبو صالح مدير لجنة المتابعة في التعليم العربي الذي أثار

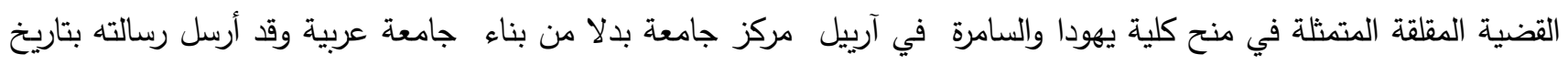

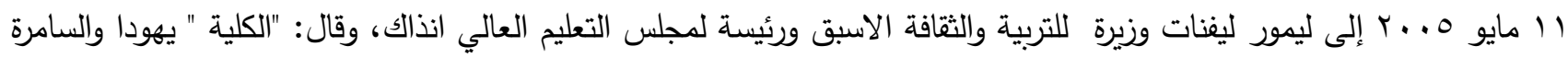

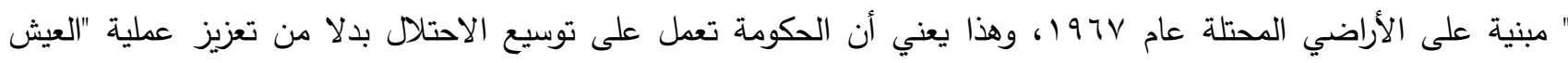

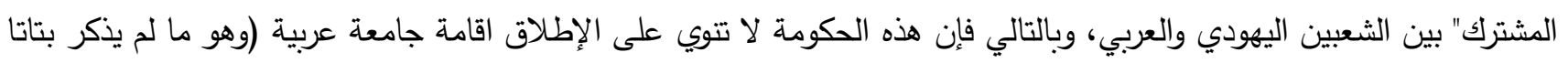

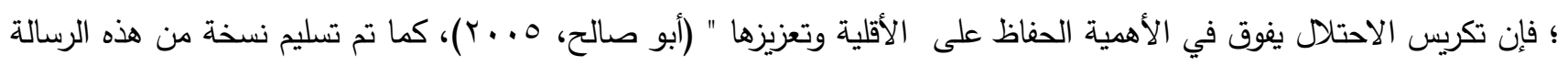

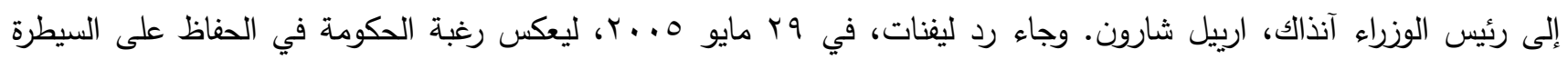

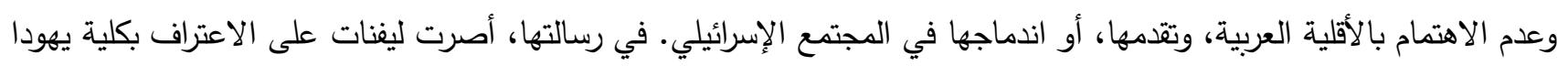

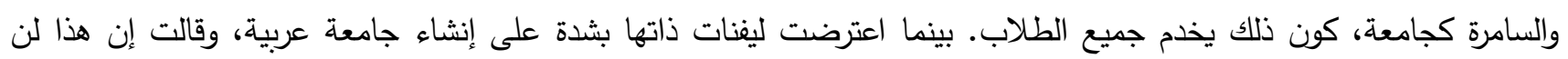
يحدث أبدا، مدعية أنها لن تسمح ببناء أي جامعة على قاعدة عرقية أو وطنية. ومع ذلك، قدمت ليفنات حلا: "إنثاء جامعة في كرمئيل، بحيث تضضوي تحت لوائها جميع الكليات في المنطقة، مثل تل حاي، الكلية الأكاديمية الجليل الغربي، كلية عيمق يزية لئراعيل

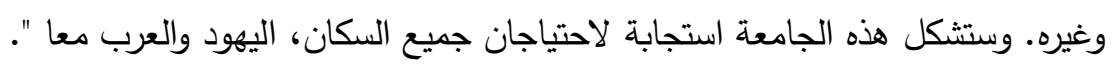

\section{محاولات إنشاء جامعة عربية}

على الرغم من كل العقبات، وخاصة الحكومية، في التعليم العالي، كانت هناك أربع محاولات لإنشاء جامعة عربية في السنوات

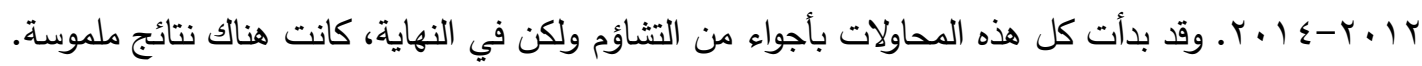




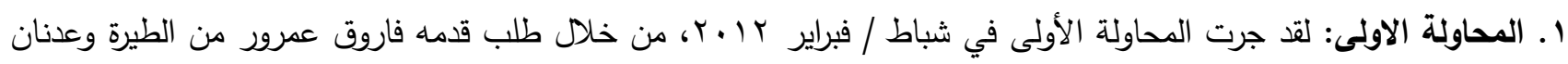

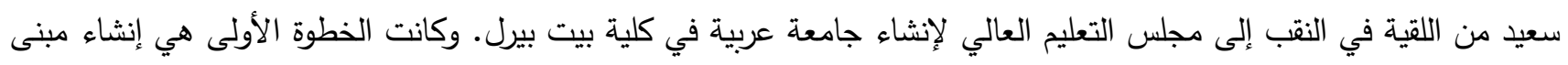

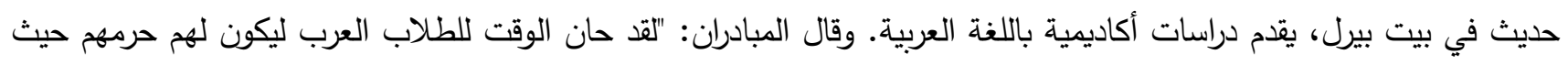

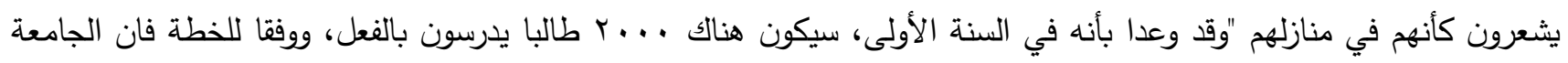

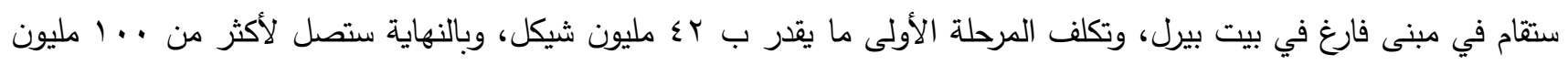

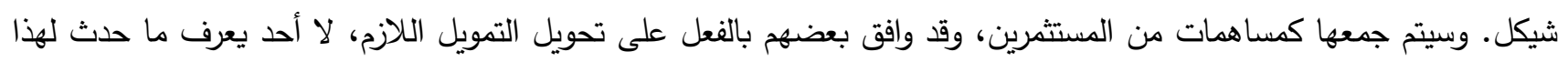

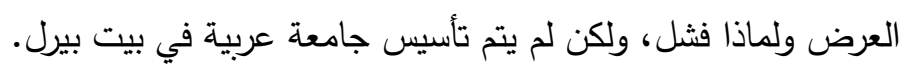

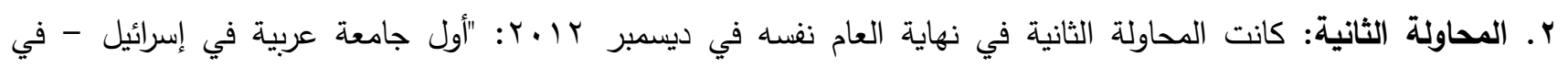

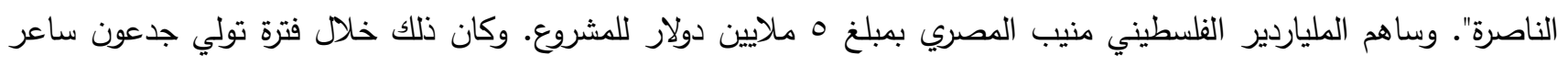
منصب وزير التربية والتعليم. وفي مقابلة تلفزيونية، قال المصري: "هذا يوم تاريخي خاص، ويسرني أن أكون هنا في الناصرة، وأن

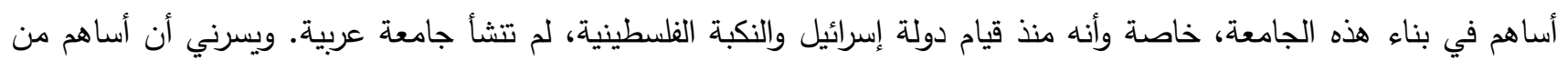
أموالي لإنثاء هذه الجامعة التي تثكل علامة مستمرة لجميع الفلسطينيين في جميع الأماكن - في إسرائيل والعالم ومناطق السلطة ولئة الفلسطينية " الا ان هذه المحاولة هي الأخرى قد أفثلت. والسبب الرئيس في افثالها يعود لتعنت وزير التربية والتعليم والحكومة التي في فئي رأت بإقامتها خطر أمني. r. المحاولة الثالثة: لقد جرت المحاولة الثالثة لاقامة جامعة عربية في اسرائيل في قرية عبلين في الجليل. وكانت هذه الجامعة

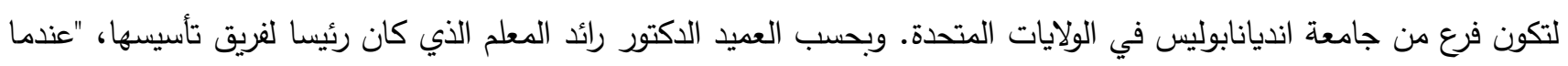
بدأنا قبل بضع سنوات، توجهنا إلى كل جامعة من الجامعات العاملة في إسرائيل، وبعضها لله فروع في أماكن مختلفة في إسرائيل -

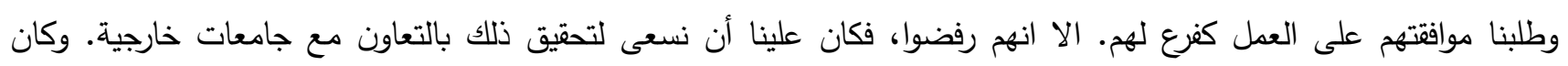

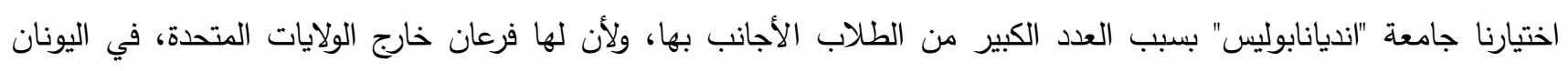
وقبرص". وذكر التقرير أيضا أنه تم تسجيل • ^ طالبا في ذلك العام في الجامعة بناءا عليه لن يكن هناك سوى ثلاثثة مجالات

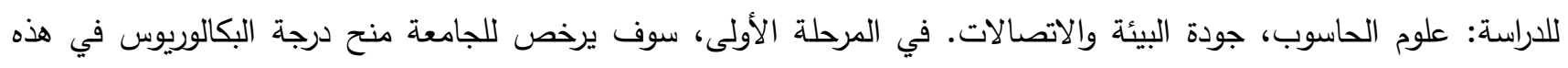
المهن. وسيتم الاعتراف بالثهادة في إسرائيل والولايات المتحدة، وستكون الدراسات باللغة الإنجليزية (وليس العربية). وتجدر الإنشارة

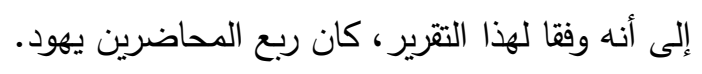

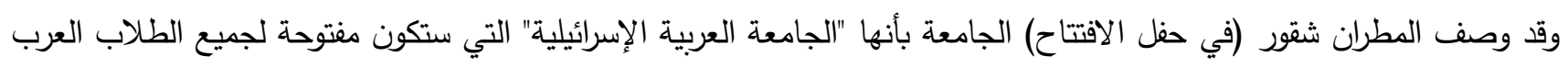

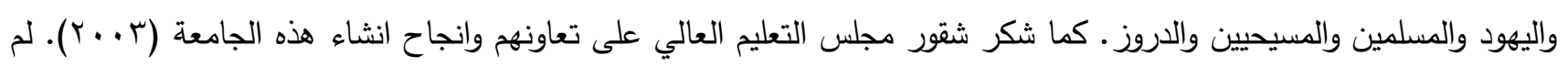
يكن هذا في الواقع جامعة ولكن فرع، ولم يدم: لم يعد موجودا اليوم.

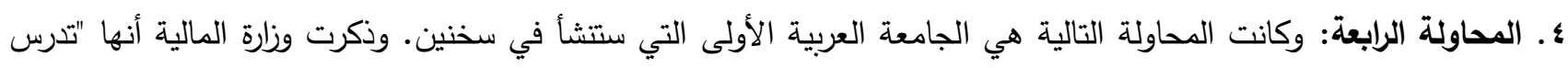
الموضوع فقط". وزار وزير المالية السابق يائير لابيد، ووزير العلوم والتكنولوجيا والفضاء السابق ايضِا، يعقوب بيري، سخئ سخنين خلال

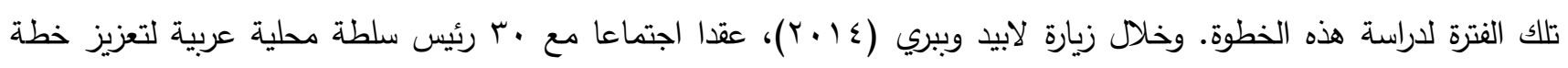

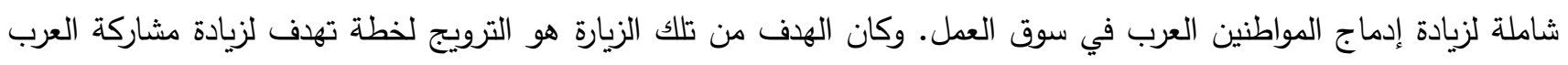

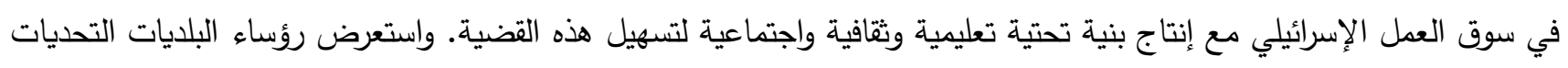
الرئيسية التي يواجهونها والموارد المطلوبة لإحداث تغيير كبير • وأعلن الوزراء للمشاركين أنهم يعتزمون، بالتعاون مع وزارتيهما، اتخاذ

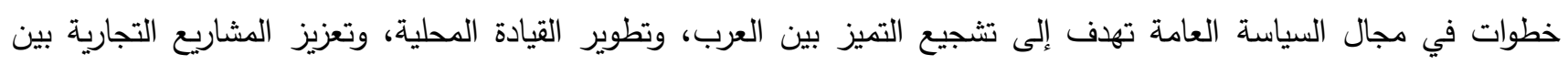
النساء العربيات. وقال لبيد:" وهذا اللقاء الثاني وهو جزء من عملية طويلة بدأناها في وزارة المالية وان دورنا كحكومة ووزارة مالية هو رعاية جميع المواطنين في إسرائيل، وقد جئنا للعمل والتوصل إلى عمق المشكلة الأساسية. لا تتوققوا عن الرغبة في تحقيق المساواة،

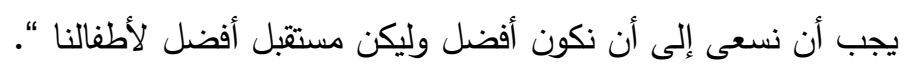


هـ المحاولة الخامسة والاخيرة: وكانت آخر محاولة لإنشاء جامعة عربية على شكل "نداء" من مجلس التعليم العالي لإنشاء معهد

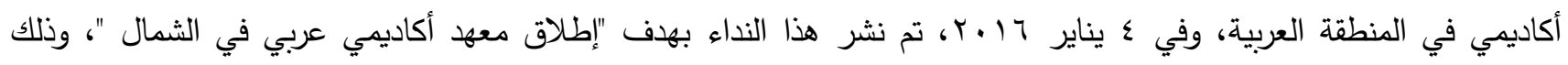

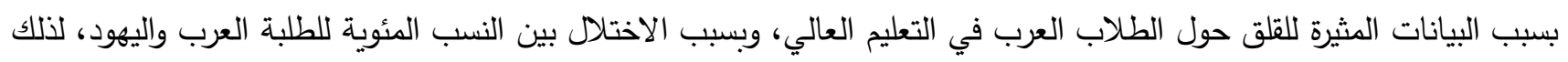
كان الغرض من هذا" النداء "هو ضمان إمكانية الوصول إلى التعليم العالي لجميع السكان العرب في إسرائيل، من جميع أنحاء البلاد.

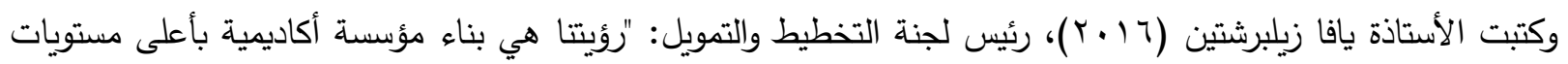

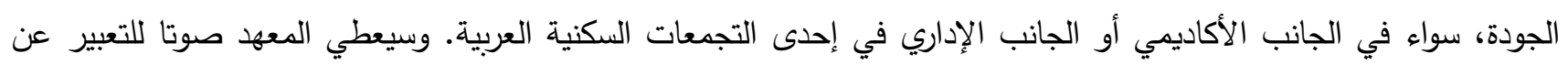
الاختلافات الواسعة القائمة بين السكان العرب وسيعبر عنها وسيكون مفتوحا لجميع السكان الإسرائيليين ".

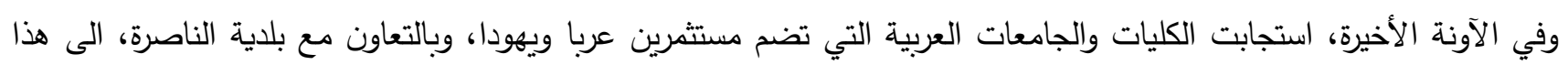
النداء الذي يحول دون أن يصبح أول حرم عربي مدرج في الميزانية في مدينة عربية. قدم مجلس التعليم العالي في النداء المعايير والثروط التالية: (1) سيتم تقديم العرض أو الاقتراح من قبل معهد للتعليم العالي يحظى باعتراف دائم من مجلس التعليم العالي،

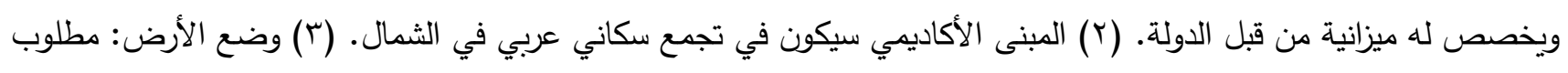

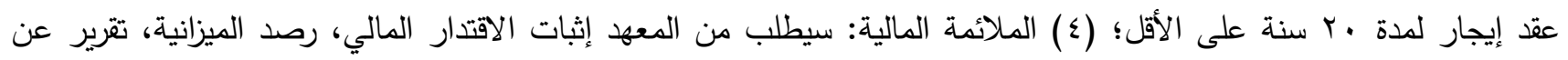

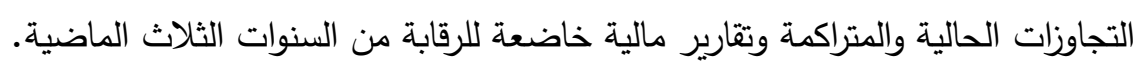
كما قدمت لجنة التخطيط والتمويل المعايير التي يجب مراعاتها عند تقييم الطلبات واختيار الفائز : (1) تكوين القيادة الأكاديمية للمؤسسة / المؤسسة المقترحة؛ (Y) وضع ومستوى أعضاء هيئة التدريس الأكاديمية العليا الذين سيعملون بالكيان

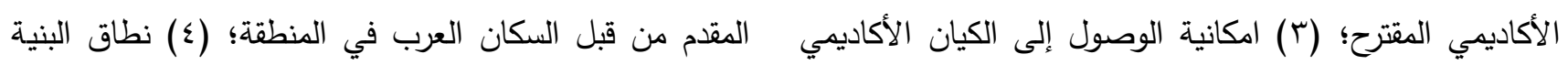

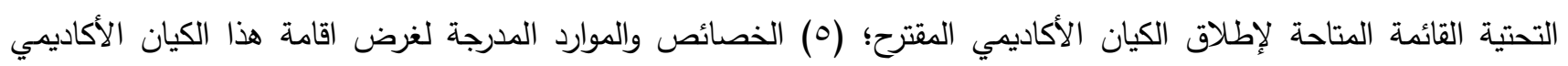

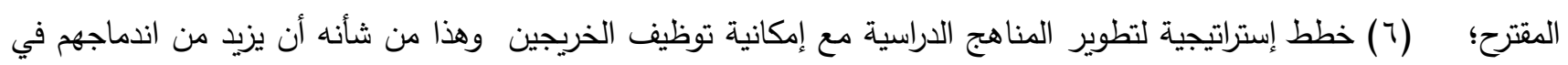

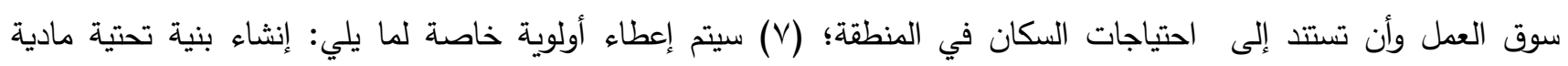

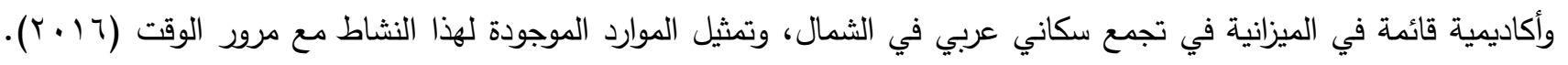

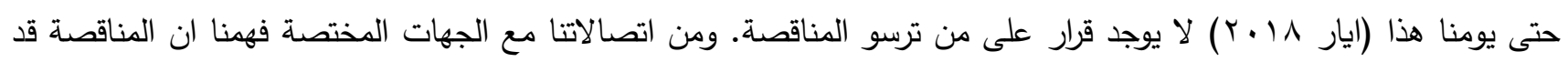
تم تجميدها الى اجل غير مسمى.

\section{تلخيص:}

تسعى الأقلية العربية الفلسطينية في إسرائيل جاهدة من أجل تأسيس جامعة خاصة بها، بحيث تكون جامعة عربية بحثية يحاضر بها بشكل رئيسي محاضرون عرب، ويكون لها حرمها الجامعي الذي يشعر الطلاب العرب بأنهم ينتمون إليه. ويرى

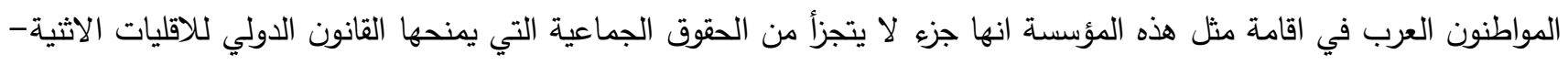
القومية. ويستشهد المواطنون العرب في محاورتهم ومقارعتهم للمؤسسة الحاكمة في إسرائيل بثأن حقهم الجماعي بالتعليم العالي باقليات عرقية واثثية في العالم الغربي. فلم يكتفي الامريكيون على سبيل المثال باقامة جامعات متعددة للاقليات الاثثية وخاصة السوداء بل راحت لأبعد من ذلك، فتضع بعض الجامعات العرق عاملا في اختيار الطلاب المتقدمين لضمان التعددية في فصولها الدراسية. وفي هذه الحالة، قد يتم قبول طلاب من أقليات عرقية في جامعات كبرى حتى لو كانوا متساوين في المعدل مع نظرائهم

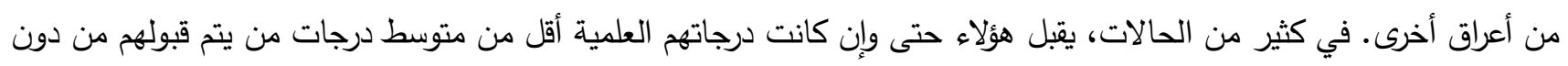
النظر إلى العرق.

ويعبر العرب-الفلسطينيون في إسرائيل في اقامة جامعة لهم عن الرغبة في إيجاد بديل للهيمنة السياسية والاقتصادية الإسرائيلية على مؤسسات التعليم في الدولة، وتشكل وسيلة لتعزيز مكانتهم ورغبة في الحفاظ على الهوية العربية والوجود والثقافة 
(أبو الهيجاء، ه . . ץ). وحتى حقيقة أن حياة هؤلاء العرب مبنية على أجواء من الصراع، وأن هذا الصراع يؤثر على التعليم العالي

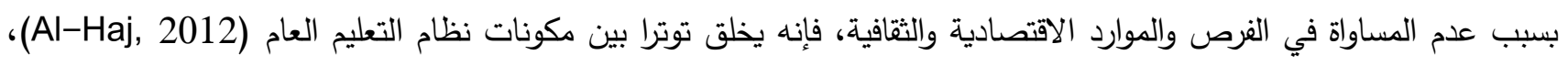
مثل الجامعات. وعلى الرغم من الخلافات العميقة بين العرب واليهود في إسرائيل، والتي يمكن أن تحد من تقدم العرب الفلسطينينين مواطني دولة إسرائيل في العديد من جوانب الحياة، فإننا نعتقد أن مثل هذه الجامعة، التي تضم كادرا اداريا وأكاديميا من المواطنين العرب المؤهلين، ستوفر مكانا للأكاديميين العرب المؤهلين الذين يعانون من تمييز في الجامعات الإسرائيلية وعدم معاملتهم اسوة

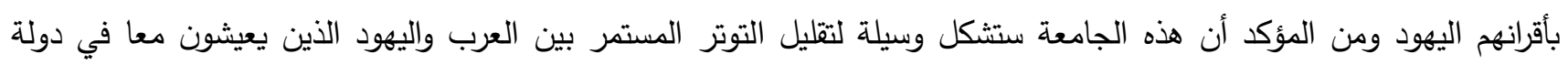
إسرائيل، وتعزيز الاعتراف المتبادل بالمساواة التامة. إن مطلب انثاء جامعة عربية بحثية مهم جدا ولا مفر منه لاى الأقلية العربية، ولجنة متابعة التعليم العربي وأعضاء

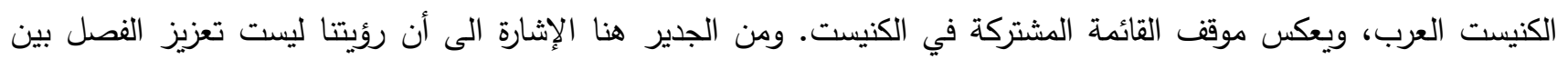

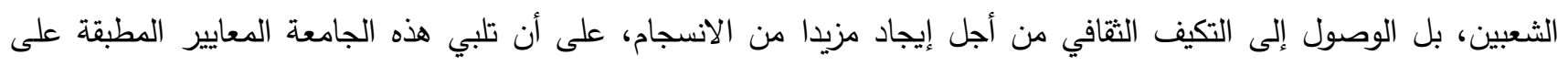
مؤسسات التعليم العالي في إسرائيل. في الواقع، الهدف من هذه الجامعة هو زيادة التكامل الاجتماعي. فالأقلية العربية-الفلسطينية في إسرائيل، ولا سيما الطبقة

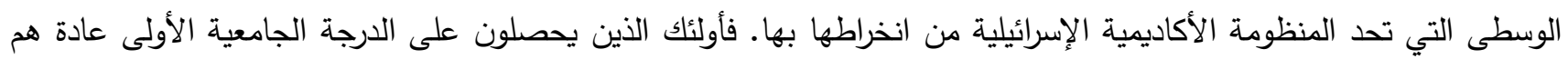
أبناء الطبقة الوسطى، وينبغي أن تتاح لهم الفرصة لتطوير ذاتهم؛ ولذلك يجب أن يدرسوا المهن التي تمس حياتهم وفي مؤسسات

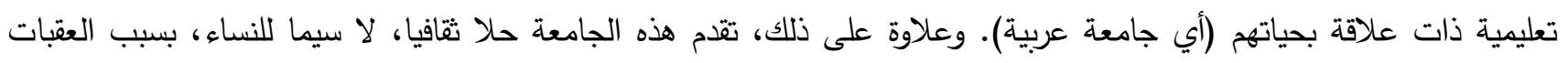

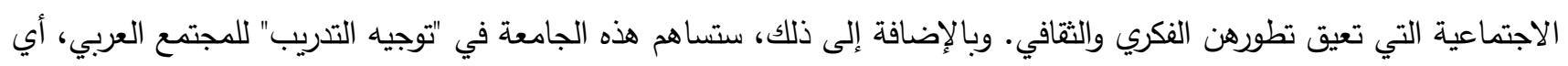

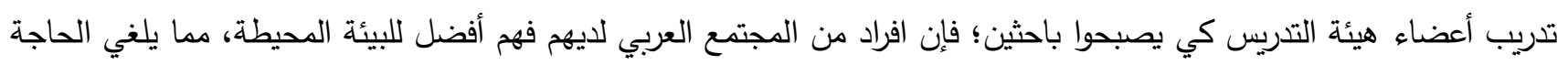
إلى جلب المزيد من الأشخاص من المجتمعات الأخرى للعمل في المجتمع العربي، وبشكل أكثر تحديد من الأكاديميين الإسرائيليين.

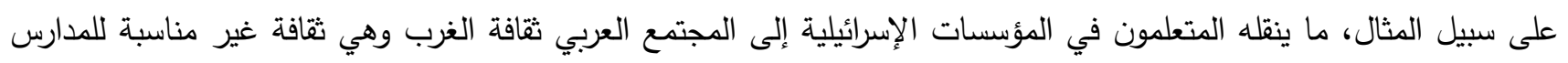

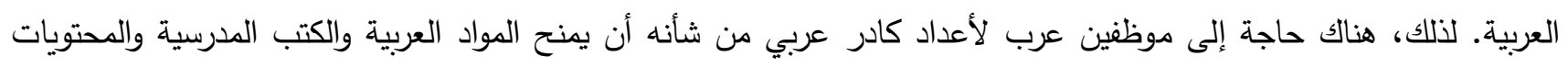
للمجتمع العربي. وعلاوة على ذلك، يمكن لهؤلاء الموظفين أن يكونوا جسرا بين المعاهد في إسرائيل والعالم العربي. وستكون هذه هذه

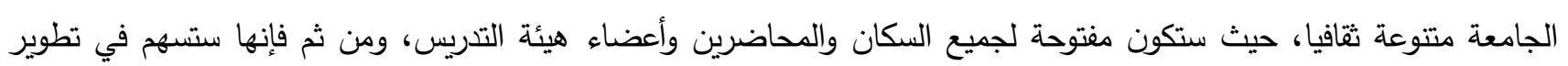

$$
\text { المجتمع العربي والمجتمع الإسرائيلي على السواء. }
$$

نحن ندرك ونرحب باقتراح مجلس التعليم العالي. ومع ذلك، فان نظرة متعمقة لاقتراح مجلس التعليم العالي تكثف عن

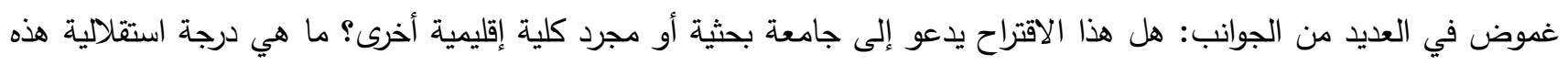

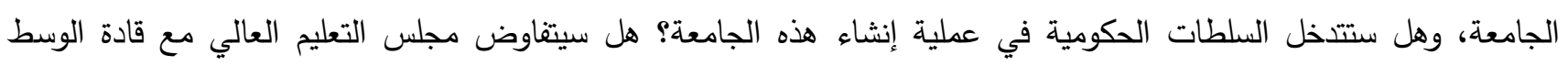
العربي ومؤسساتهم الممثلة مثل لجنة المتابعة للتعليم العربي والمجلس التربوي للتعليم العربي؟ هل تم البحث عن المهن التهن الأكثر استصوابا للدراسة، ولغة التدريس ودرجة التعددية للجامعة؟ هل هناك منطقة جغرافية مناسبة يمكن الوصول إليها من قبل معظم السكان العرب ومن مناطق مختلفة وهل هناك منطقة في المدن العربية الكبيرة مناسبة لإقامة جامعة عربية؟ هل ستحظى هذه هنه الجامعة بثقة الطلاب العرب، وهل سيفضلونها على الجامعات الأخرى؟ هل توفر حلا مناسبا لجميع الطلاب؟ هل سيكون هناك

$$
\text { تمثيل مناسب للمحاضرين العرب؟ }
$$

بالإضافة إلى ذلك، ندرك أن إنشاء جامعة عربية يطرح العديد من التحديات، والسؤال هو ما إذا كان مجلس التعليم العالي

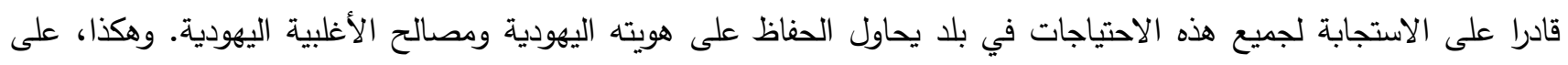

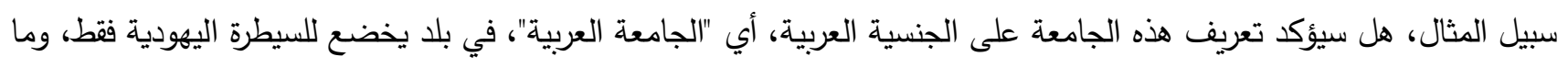

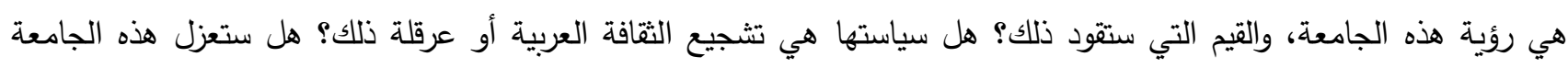

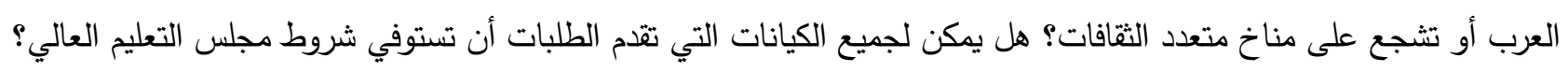


نريد أن نؤمن بأنه على الرغم من الإعلانات والإنكار والمحاولات والإخفاقات والعقبات والمعضلات والتحديات، فإنه لا بد من ان نرى محاولة جادة وأساسية لإنثاء جامعة عربية كضرورة ملحة للعرب الفلسطينيين مواطني دولة إسرائيل.

ا. أبو الهيجاء، ي.(0 . . ب). لماذا لا توجد جامعة عربية في إسرائيل؟ في: غور -زئيف، أ. (محرر). نهاية الأكاديمية في

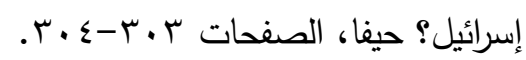
r. أبو سعد، ا.، هورويتز ، ت.، وأبو -سعد، أ ـ (V . . . r). نسج التقاليد والحداثة: النساء العربيات البدويات في التعليم العالي.

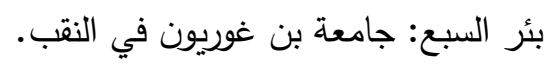

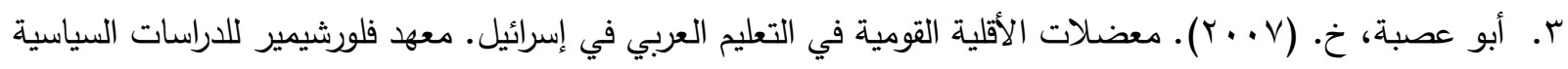
(باللغة العبرية).

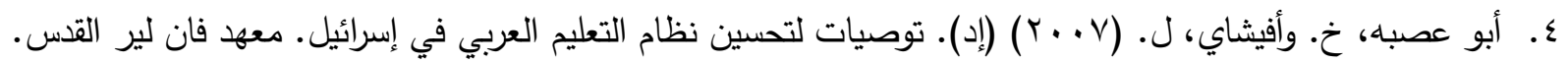

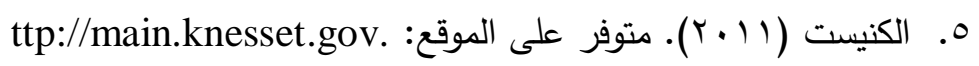

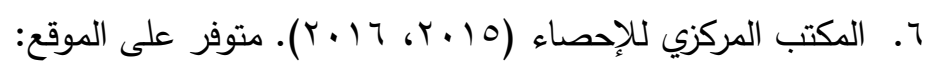
http://www.cbs.gov.il/reader/shnatonhnew_site.htm

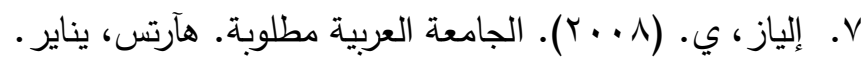

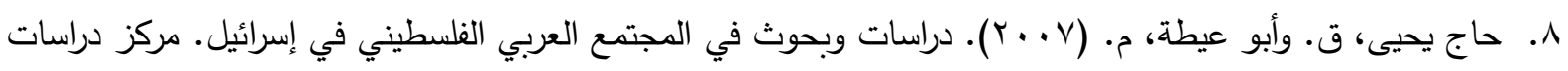

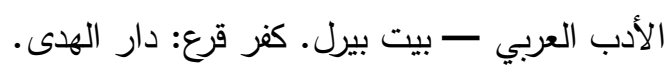

9. حيدر، ع. (997 (19). الفلسطينيون في إسرائيل في ظل اتفاقية أوسلو • بيروت: مؤسسة الدراسات الفلسطينية.

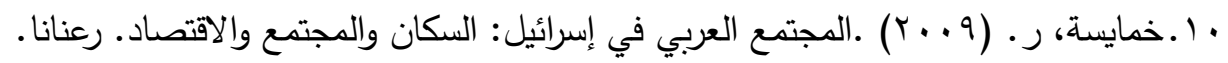

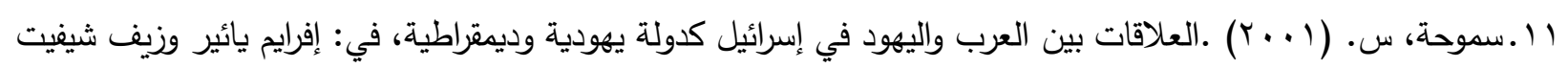

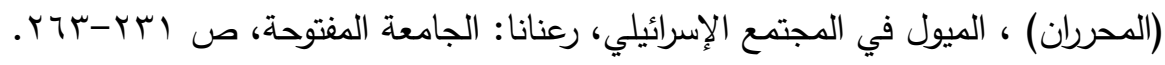
Y 1. عدالة. (1 (1). تقرير عدم المساواة: الأقلية العربية الفلسطينية في إسرائيل - عدالة - المركز القانوني لحقوق الأقلية

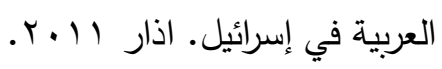

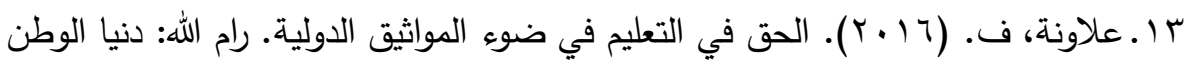

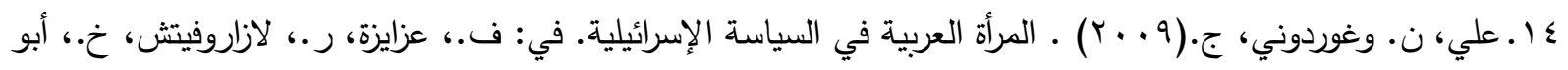

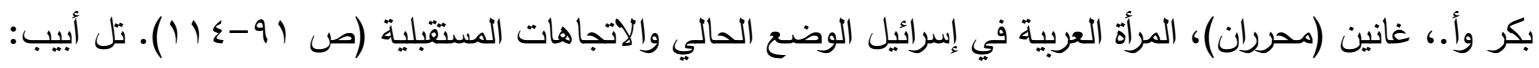
راموت برس. (باللغة العبرية).

1 ا. علي، ن. (991 (1). الحركة الإسلامية في إسرائيل: الأيديولوجيا والأهداف والخصائص الفريدة. حيفا، جامعة حيفا.

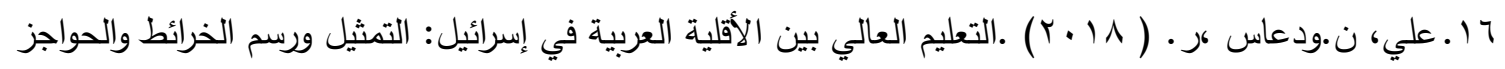
والتحديات. تل ابيب، رسلنج (باللغة العبرية).

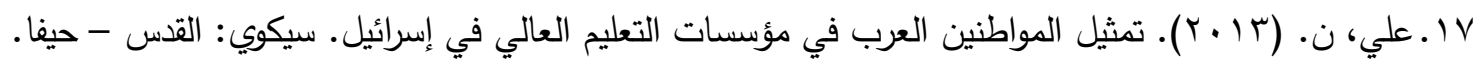

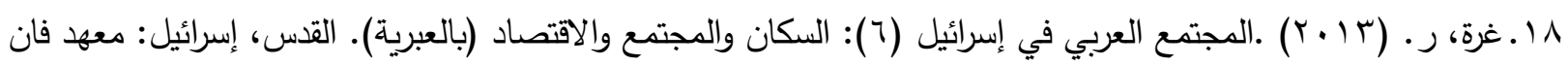
لير في القدس، دار نشر هاكيبوتس هؤحاد. 9 ( ـفرح، ج. (99V (1) ). جامعة عربية للتعليم والبحث والخبرة والواقعية. ورقة سلوك: جمعية التوجيه التربوي للطالب العربي، 


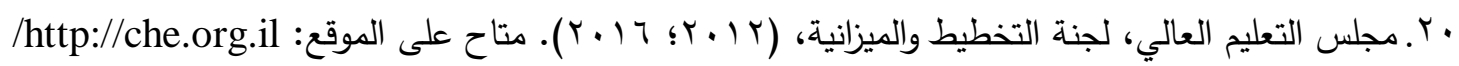

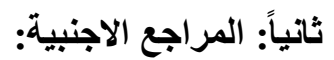

[1] Abu-Hussain, J. (2015). Professional Socialization in Teaching-Training Colleges in the Arab Education System in Israel. American Journal of Educational Research, 3(11), 14691475.

[2] Abu-Hussain, J., Tilchin, O., \& Essawi, M. (2015). A Teacher Accountability Model for Overcoming Self-Exclusion of Pupils. International Education Studies, 8(9), 58.

[3] Abu-Rabia-Queder, S. \& Arar, K. (2011). Gender and higher education in different national spaces: Female Palestinian students attending Israeli and Jordanian universities. Compare: A Journal of Comparative and International Education, 41(3), 356.

[4] Abu-Saad, I. (2006). State-Controlled Education and Identity Formation among the Palestinian Arab Minority in Israel, American Behavioral Scientist, 49 (8), 1085-1100.

[5] Abu-Saad, I. (2015). Access to higher education and its socio-economic impact among Bedouin Arabs in Southern Israel. International Journal of Educational Research. available at: http://www.sciencedirect.com/science/article/pii/S0883035515000580

[6] Al-Haj, M. (2003). Higher education among the Arabs in Israel: Formal policy between empowerment and control. Higher Education Policy, 16(3), 351-368.

[7] Al-Haj, M. (2012). Education, empowerment, and control: The case of the Arabs in Israel. Suny Press.

[8] 'Ali, N. (2004). Political Islam in an Ethnic Jewish State. Its Historical Evoluation and Contemporary Challenge. Holy Land Studies Journal 69-92, Twickenhem Edinburg University Press

[9] 'Ali, N. \& Da'as ,R. (2016). Arab Women in Israeli Politics: Aspirations for Fundamental Equality or Preservation of Gender Inequality?.Cultural and Religious Studies, 4(2), 67-86.

[10] Ancis, J. R., Sedlacek, W. E., \& Mohr, J. J. (2000). Student perceptions of campus cultural climate by race. Journal of Counseling and Development, 78, 180-185.

[11] Arar, K., \& Haj-Yehia, K. (2013). Higher education abroad: Palestinian students from Israel studying in Jordanian universities. Journal of Applied Research in Higher Education, 5(1), 95-112.

[12] Arar, K., \& Haj-Yehia, K. (2016). Higher Education and the Palestinian Arab Minority in Israel. New York: Palgrave Publication .

[13] Arar, K., \& Mustafa, M. (2011). Access to higher education for Palestinians in Israel. Education, Business and Society: Contemporary Middle Eastern Issues, 4(3), 207-228.

[14] Back, L. (2004). Ivory Towers? The Academy and Racism, Institutional racism in higher education, 1-6.

[15] Boliver, V. (2017). Misplaced optimism: how higher education reproduces rather than reduces social inequality. British Journal of Sociology of Education, 38(3), 423-432.

[16] Canton, E. (2002). Higher education reform: Getting the incentives right. Hauge, The Netherlands: CPB Netherlands Bureau for Economic Policy Analysis.

[17] Canton, E. (2003). Private contributions and accessibility of higher education: Experiences from Australia and the Netherlands. Hauge: CPB Netherlands Bureau for Economic Policy Analysishhttp://www.cerc.gouv.fr/meetings/seminairenovembre2002/canton.PDFi 
[18] Connor, H. (2002). A good job, a better paid job, and a better choice of job: The economic benefits of higher education from an individual perspective. Journal of Adult and Continuing Education, 8(1), 5-13.

[19] Connor, H., \& Dewson, S. (2001). Social class and HE: Issues affecting decisions on participation by low social class groups. In DfES research report 267. Department for Education and Skills.

[20] Connor, H., Tyers, C., Modood, T., \& Hillage, J. (2004). Why the difference? A closer look at higher education minority ethnic students and graduates In DfES research report 552. DepartmentforEducationandSkills hhttps://www.education.gov.uk/publications/eOrderingDownload/RR552.pdfi.

[21] Da'as, R. (2017). School principals' leadership skills: measurement equivalence across cultures. Compare: A Journal of Comparative and International Education, 47(2), 207-222.

[22] Harwood, S. A., Huntt, M. B., Mendenhall, R., \& Lewis, J. A. (2012). Racial microaggressions in the residence halls: Experiences of students of color at a predominantly White university. Journal of Diversity in Higher Education, 5(3), 159.

[23] Hasson, S. (2006). Barriers to Development and Equality between Arabs and Jews in Israel: A Proposal for a Framework of Thought. In S. Hasson \& M. Karayanni (Eds.), Barriers to Equality: The Arabs in Israel. Jerusalem, IL: The Floersheimer Institute for Policy Studies.

[24] Hurtado, S., Griffin, K. A., Arellano, L., \& Cuellar, M. (2008). Assessing the value of climate assessments: Progress and future directions. Journal of Diversity in Higher Education, 1(4), 204-221.

[25] Levy, D. (2015). Private higher education: Patterns and trends. International higher education, (50).

[26] Loo, C. M., \& Rolison, G. (1986). Alienation of ethnic minority students at a predominantly White university. The Journal of Higher Education, 58-77.

[27] Marginson, S. (2008). Global field and global imagining: Bourdieu and worldwide higher education. British Journal of Sociology of Education, 29(3), 303-315.

[28] McClelland, K. E., \& Auster, C. J. (1990). Public platitudes and hidden tensions: Racial climates at predominantly White liberal arts colleges. The Journal of Higher Education, 607642.

[29] Rankin, S. R., \& Reason, R. D. (2005). Differing perceptions: How students of color and White students perceive campus climate for underrepresented groups. Journal of College Student Development, 46(1), 43-61.

[30] Shapira, T., Arar, K., \& Azaiza, F. (2011). 'They didn't consider me and no-one even took me into account': Female school principals in the Arab education system in Israel. Educational Management Administration \& Leadership, 39(1), 25-43.

[31] Suen, H. K. (1983). Alienation and attrition of Black college students on a predominantly White campus. Journal of College Student Personnel, 24(2), 117-121.

[32] Thompson, R., \& Simmons, R. (2013). Social mobility and post-compulsory education: revisiting Boudon's model of social opportunity. British Journal of Sociology of Education, 34(5-6), 744-765.

[33] Vaccaro, A. (2014). Campus Climate for Diversity: Current Realities and Suggestions for the Future. Texas Education Review, 2(1), 129-137. 


\title{
Education as a Collective Right: Arab University in Israel - Challenges, Obstacles and Possibilities
}

\author{
Dr. Nohad Ali \\ Senior Lecturer and Senior Researcher at Western Galilee College and the University of Haifa \\ NohadAli@univ.haifa.ac.il
}

Dr. Rima'a Da'as

Lecturer and researcher in education at Al- Qasemi College of education rimaajd@gmail.com

\begin{abstract}
:
The idea of establishing an Arab university in Israel is much debated, particularly within Arab society, Jewish society, and at Israeli institutions where it has met with a great deal of opposition. The vast majority of the Arab public consider establishing an Arab university to be an opportunity to serve the Arab citizens of Israel and reinforce their status, while protecting their identity, culture and existence. We also observe a wide consensus among the social elite who study at Israeli academies concerning the existence of an Arab university as one of the most essential collective rights of the Palestinians in Israel. Those who advocate establishing an Arab research university consider it to be a response to the marginalization and national- and cultural-exclusion policies suffered by Arab students in the academic sphere, while detractors suggest that establishing such a university will hinder the graduates' integration into the Israeli labor market on the one hand, and will increase marginalization and encourage Arab extremism and hostility toward the Israeli state on the other.

This research paper discusses the vision of establishing an Arab university: the barriers and obstacles, the inequality in academic rights, and the way in which this dream can be fulfilled. This paper also deals with three phenomena: "Jordanization" and "Palestinization" of higher education, namely, studying in Jordan and in Palestine, respectively, and globalization of higher education, i.e., studying in Western and other countries. The study presents the most recent data on higher education among Arab Palestinians in Israel.
\end{abstract}

Keywords: Arab university, Arab culture structure, national ethnic minority, national racism, marginalization, Israeli political structure. 